Article

\title{
Consumer Preferences for Different Designs of Carbon Footprint Labelling on Tomatoes in Germany-Does Design Matter?
}

\author{
Stephan G.H. Meyerding ${ }^{1,2, *}$, Anna-Lena Schaffmann ${ }^{3}$ and Mira Lehberger ${ }^{4}$ \\ 1 Department of Agricultural Economics and Rural Development, Georg-August-Universität Göttingen, \\ 37073 Göttingen, Germany \\ 2 Department of Nutritional Sciences, Hochschule für Angewandte Wissenschaften Hamburg \\ (HAW Hamburg), 21033 Hamburg, Germany \\ 3 Faculty of Economic Sciences, Georg-August-Universität Göttingen, 37073 Göttingen, Germany; \\ schaffmann.lena@gmail.com \\ 4 Department of Fresh Produce Logistics, Hochschule Geisenheim University, 65366 Geisenheim, Germany; \\ mira.lehberger@hs-gm.de \\ * Correspondence: stephan.meyerding@haw-hamburg.de; Tel.: +49-40-428-75-6394
}

Received: 1 February 2019; Accepted: 11 March 2019; Published: 15 March 2019

check for updates

\begin{abstract}
The climate impact of tomato production is an important issue in the sustainability of tomatoes, especially in northern European countries, such as Germany. Communicating the climate impact of products to the consumer is difficult and the design of the label might be the key to its success. For this reason, the present study compares the utilities of six different carbon footprint labels to evaluate which label design works best for the consumer. 598 consumers were surveyed in a representative online choice-experiment. The participants had to choose between tomatoes with different product characteristics, such as origin, price, organic label, and carbon footprint label. A split sample approach was used where each sub-sample with around $n=100$ saw a different carbon footprint label design in the choice-experiment. The results suggest that qualitative carbon footprint labels using color-coded traffic light labelling are superior to those that claim climate impact reduction or neutrality, including those that provide more details regarding the climate impact of the product and the company. The latent class analysis with four consumer segments shows that a significant proportion of consumers in Germany would consider a carbon footprint label as an important characteristic.
\end{abstract}

Keywords: product carbon footprint label; marketing; consumer preferences; choice-based con-joint analysis; latent class analysis

\section{Introduction}

Carbon footprint labelling has received much attention in recent years due to its potential to reduce emissions from food consumption. The carbon footprint label is also an attempt to use the climate friendliness of a product as a selling point. A deeper understanding of consumer behavior regarding the communication of the environmental impacts of food products, especially regarding climate label designs, is of importance in altering consumption patterns to benefit the environment [1].

The aim of carbon footprint labelling is to inform consumers regarding the amount of emissions that are produced by a certain product over its entire lifecycle, as indicated in grams of carbon equivalents. Therefore, it allows for consumers to differentiate between high-climate-impact and low-climate-impact products [2]. 
From a theoretical economic point of view, consumption decisions are the result of a utility maximizing process that was carried out by consumers. Most economists concur that individuals can derive utility not only from material sources, but also from non-material ones [3,4]. Consequently, most consumers do not exclusively care about the price of a product, but also about attributes, such as the environmentally friendliness of the production process. In the case of carbon-labeled products, studies identified a number of socio-demographic factors, which have an effect on to the willingness to pay for these products, such as occupation and income level [5]. Additionally, consumers significantly differ with respect to education and age [6], and the effect of carbon labelling has been found to be significantly stronger the more environmentally concerned consumers [2].

In general, the overall objective of a label, such as the carbon footprint label, is to reduce the information asymmetry between producers and consumers [7]. In particular, consumer at the POS cannot verify the credence attributes, such as climate friendliness [8]. Thus, while making a purchasing decision, the consumer is reliant on the ability of the label to communicate information about the climate friendliness of the product quickly and in an intuitively understandable way.

The carbon footprint label mostly appears in three different forms depending on the communication objective (illustrated in Figure 1, group 1). The Carbon Trust label communicates the product's greenhouse gas emissions over its entire lifecycle [9]. The second label communicates the company's commitment to reducing emissions [10]. Finally, the third communicates the carbon neutrality of a product [11].

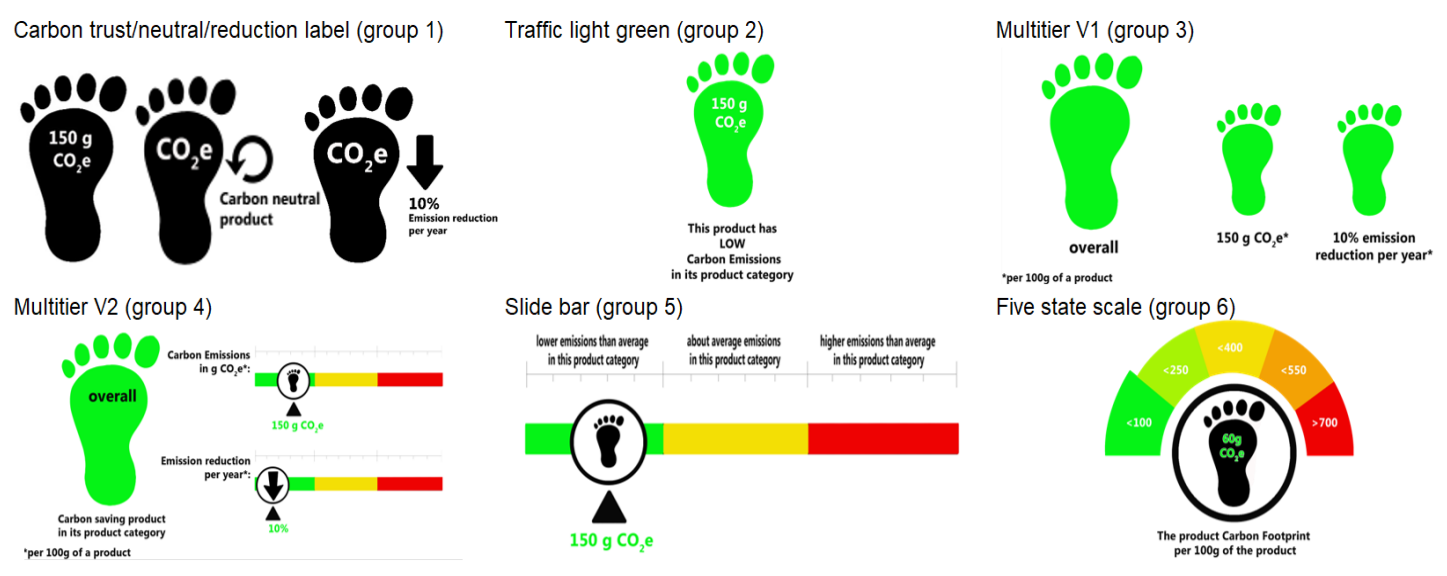

Figure 1. Carbon footprint designs of this study.

Several studies [1,12-14] revealed that consumers do not adopt the black footprint-as initiated by the Carbon Trust in 2001 and later implemented in the retail sector by Tesco in 2008. For this reason, Tesco stopped its carbon footprint program in 2012 due to insufficient uptake. The interpretation of the label turned out to be difficult for the average consumer. This is due to the fact that consumers are not able to classify an abstract number of greenhouse gas emissions. Therefore, consumers are left to interpret, for themselves, what the number means and whether it is a high-climate-impact or low-climate-impact product. On the basis of the unclear message of the current design of the carbon footprint label and the difficulty in interpretation, [14] the evaluation of different part-worth utilities of different designs of the carbon footprint label as an interesting challenge for future research was identified.

Some studies [1,2] have investigated how the design of carbon footprint labels may be optimized to increase the effectiveness of this label in terms of influencing consumer decision-making. The findings emphasize the fact that the key information in the label should be more intuitively understandable to every consumer. They point out that the actual design is not coherent to the average consumer and then highlight the dilemma between the necessity of detailed information for the customer to 
understand carbon footprint labelling and the disadvantages of information overload at the point of sale (POS).

Overall, the relatively low impact of the carbon footprint label on consumer decision-making, in comparison with other food attributes, contrasts with the increasing interest of consumers in the environmental impact of food $[10,12]$. Hence, it comes to mind that a major reason for this gap occurs because the actual design is not able to translate consumer needs into action. Moreover, recent studies on other eco-labels support that consumers' understanding of the information, such as label aims to convey-and therefore its effectiveness in altering purchasing decisions-depends on subtle details regarding the design implementation [8,15-17].

Currently, the carbon footprint label communicates a continuous variable-the amount of emissions that a certain product causes over its entire lifecycle, as indicated in grams of carbon equivalents. This infinite number of possible emission values is not intuitively comprehensible for the average consumer. Continuous variables show a certain degree of complexity in terms of interpretation [8]. The average consumer may not be able to evaluate whether a product is climate friendly or not by only seeing an abstract number. Thøgersen and Nielsen [2] investigated the extension of the original carbon footprint label with traffic light color-coding. This method is common in nutritional labeling, because it transfers abstract numbers conveying complex nutritional information into accessible multi-level labelling systems [18]. Thøgersen and Nielsen [2] proposed an improvement of the effectiveness of the original carbon footprint label by making its key information more intuitively understandable to the average customer. The effectiveness of traffic light color-coding in the food labelling context is based on insights in consumer decision-making [19] and behavioral economics [16].

Furthermore, the implementation of traffic light labels allows positive as well as negative labelling. The aim of the latter is to alter consumption patterns away from environmentally harmful products. A study by Grankvist, Dahlstrand and Biel [20] revealed that negative labelling has a higher and longer lasting impact on purchase behavior than positive labelling. Accordingly, a carbon footprint design that uses traffic light labelling—as compared to a binary carbon footprint label—offers the opportunity to label the environmental friendly (green), the neutral (yellow), as well as the environmentally harmful (red) products. This type of label is called a three-tier label.

As described earlier, a dilemma exists: On the one hand, there is a strong need for detailed information at the consumer level to properly understand the carbon footprint labelling system. On the other hand, information overload at the point of sale negatively affects the effectiveness of carbon footprint labelling [21]. In this context, it would be interesting to examine the right level of information to make available to the consumer in order to solve this dilemma and gain acceptance among consumers. One approach would be to extend the three-tier label to a five-tier label or to add more dimensions (e.g., carbon reduction) to the label in order to provide more complete information to the consumer.

This study proposes and tests carbon footprint labelling taking the approach of Thøgersen and Nielsen [2] one step further. One assumption is that increasing the information content by adding dimensions, such as carbon reduction, can refine the effectiveness of the label. A second assumption is to extend the three-tier label to a five-tier label in order to extend the effect of positive and negative labelling.

The present study's aim is to improve the effectiveness of carbon footprint labelling by investigating the different design alternatives as an option for reducing emissions from the food sector, focusing on consumer perceptions and with the reservation that the optimization of carbon footprint labelling is still at an early stage in Germany and elsewhere.

The lack of research on how the effectiveness of a carbon footprint label can be increased by optimizing its design leads to the following research questions: What are the shopping preferences of consumers for tomatoes regarding different designs of carbon footprint labels? Is there an association between food- and buying-related factors and the effectiveness of the carbon footprint label? 


\section{Materials and Methods}

In this study, fresh tomatoes were used as a research object, because they are-with an average of $26.2 \mathrm{~kg}$ per person in the fiscal year 2015/2015 — by the far the most popular vegetables in Germany [22]. Additionally, organic tomatoes have the second highest market share on the German market for fresh vegetables [23].

The questionnaire that was used in this study consisted of five parts. The first part elicited the participants' socio-demographic characteristics. The participants were randomly split into six groups after this set of initial questions. In the second part, each group went through a choice experiment, in each case with one out of the six design alternatives of the carbon footprint label, whereby every group's choice-set is based on a different carbon footprint label design. A total of 84 different choice sets (14 different choice sets per group) were generated. Fourthly, the respondents were to state their individual preferences and perceptions towards purchase preferences regarding tomatoes, environmental awareness, eco-labelling, eating behavior, cooking, and consumption while using Likert scales. The last part contains a short quiz with seven questions to test the participants' knowledge related to carbon footprint labelling.

The data collection took place in Germany in September 2017 via an online access panel. To obtain results that were similar to those for the German population, quotas were set for age, gender, place of residence, and income. Still, the study is exploratory and we make no claims for generalizability [24]. Statistical computations such as part-worth utilities are descriptive, and thus must be seen as preliminary evidence.

A screen-out was set for the option "no tomatoes bought in the last two weeks". The outcome was 168 screen-outs, 555 quota-fulls, and 22 early terminations. Therefore, the evaluation resulted in 589 data sets, which could be considered as fully completed.

\subsection{Choice-based Conjoint Analysis}

Within the last decades, choice-based conjoint analysis (CBCA) has increased in popularity in marketing as well as in preference research. CBCA enables the interpretation and estimation of consumers' purchase behavior and preferences. These behaviors and preferences originate in a choice between different products with different product attributes. In accordance with economic theory, the basic presumption of this approach is that consumers gain utility from the specific combinations of material and non-material attributes, rather than from the mere product itself. The CBCA generates so-called part-worth utilities for the different attribute levels [25] (pp. 179 ff.). Generally speaking, the higher the part-worth utility is, the more preferred the attribute level. The part-worth of one level within each attribute is set to zero here. The remaining levels are then estimated in contrast with respect to zero. Additional information is provided by the relative importance of each attribute in terms of percentage, which add up to $100 \%$. Thus, the higher the percentage calculated for the attribute (e.g., climate label, price), the more important is this attribute for the consumption decision [26]. The Hierarchical Bayes (HB) approach was the basis for calculating part-worth utilities and the relative importance of attributes. The HB estimate, like the CBCA, was performed using the Lighthouse Studio 9 software. The program uses the Monte Carlo Markov Chain algorithm. The value for the fit statistics (RLH) ranges between 0.3 and 0.33 .

The CBCA offers some valuable advantages when compared to other methods-especially from a methodological and practical point of view [27]. Firstly, the CBCA offers a more realistic approach to data collection regarding consumer preferences. This is due to the implementation of a simulated purchase situation. The second advantage is that the resulting part-worth utilities represent the actual impact of the different attributes on product choice [25] (p. 174). Thirdly, different part-worth utilities of the product can be assessed by directly applying specific characteristics of a product in the conjoint analysis [28].

It is assumed that forced choice might affect the outcomes of a choice experiment [29]. For this reason, the CBCA offers to integrate a "no-buy" option. 


\subsection{Latent Class Analysis}

The latent class (LC) analysis allows for simultaneous estimation of utility values for different groups. This approach assumes that a certain number of not directly observable groups (latent classes) exist in a sample, wherein the allocation of the individual participants to the groups is performed based on different preferences. These preferences are the part-worth utilities of the investigated characteristics. The basic idea is that, although the survey participants can be assigned to a specific segment or group, the allocation is only possible with a certain probability due to incomplete information. Thus, a test person is not only allocated to a single cluster, but-with different probabilities-to all clusters. On the one hand, this might complicate the interpretation of the results since the individual may not be clearly assigned to a cluster. On the other hand, there is the possibility to use the answers of a person not only to determine one, but all utility functions, and thus also to improve the weak information situation for a group-specific consideration [30].

\subsection{Food-Related Lifestyles and Labelling and Buying-Related Factors}

Food-related lifestyles are an instrument that was introduced by Brunsø, Grunert and Bredahl [31]. It is used broadly to measure attitudes towards food, purchase behavior, as well as food preparation and consumption. The food-related lifestyle approach offers an opportunity to marketing research to identify further material and non-material drivers of food consumption decisions and examine their relevance in segmenting consumers.

The foodie items in this study were directly chosen from the food-related lifestyle scale items of Gunarathne et al. [32]. They are based on the approach of Brunsø, Grunert and Bredahl [31] and they were adjusted to fit the German food culture. The instrument consists of 28 items regarding quality aspects of food, attending culinary events, pleasure, and interest concerning food, novelty preferences, eating in company, passion for cooking, subjective knowledge, and cooking skills.

Alongside food-related lifestyle, labelling and buying-related factors are considered in this study. Ten additional items were directly chosen from the individual ecolabel adoption process scale of Thøgersen, Haugaard and Olesen [33]. Furthermore, ten items were included in order to identify the relevant characteristics of consumers regarding food labelling and time pressure [8].

\subsection{Multiple Regression}

The findings of the different applied methods were used to test their influence on the relative importance resulting from the CBCA for the attributes of origin, price, organic label, and climate label. Additionally, respondents' high or low performance in a quiz on their carbon footprint knowledge was included as an independent variable in the regressions. Here, seven multiple-choice questions were chosen to test the familiarity of the respondents with carbon footprint related topics. The quiz is conducted at the end of the questionnaire, so as not to bias the decisions of the respondents in the choice-experiment. The questions vary between "Which greenhouse gas is mainly responsible for the global temperature increase of recent years?" and "How is the carbon footprint of a product calculated?".

Overall, the regression results are valuable in themselves, as they identify the drivers of the relative importance of the attributes. Moreover, results can be used to draw conclusions regarding underlying consumer preferences and behavior in the identified consumer segments.

\subsection{Experimental Design}

Several studies have tested one, two, or all of the three forms of the original carbon footprint label that was introduced earlier $[1,10,14]$. The designs communicate the greenhouse gas emissions throughout a product's lifecycle, a company's commitment to reduce emissions, or the carbon neutrality of a product. This study tests four design extensions (Figure 1) that are based on the traffic light labelling approach of Thøgersen and Nielsen [2]. 
The carbon footprint (CF) design alternatives were created with Adobe Photoshop and they are based on the theoretical principles that are discussed earlier.

The respondents were not provided with any definition of carbon footprint labelling before starting the CBCA task. Every participant was only shown one of the six design alternatives depending on the group that they were randomly assigned to. Every label design has a different degree of complexity. Each of the labels represented one of the following:

- $\quad$ The three original forms (Figure 1, group 1):

C CF indicated numerically: $150 \mathrm{~g}$ CO2-equivalents per $100 \mathrm{~g}$ of product

- Carbon neutral due to greenhouse gas emission compensation

- Company is committed to reducing its greenhouse gas emissions by $10 \%$ per year

- CF indicated by a traffic light color-coding scheme (three-tier label: green (low), yellow (neutral), and red (high)) (Figure 1, group 2)

- $\quad \mathrm{CF}$ indicated by a traffic light color-coding scheme and combines three dimensions (indicated numerically: $150 \mathrm{~g} \mathrm{CO}$-equivalents per $100 \mathrm{~g}$ of product; company's commitment to reducing its greenhouse gas emissions by $10 \%$ per year), which results in an overall evaluation (Figure 1, group 3)

- CF indicated by a traffic light color-coding scheme and combines three dimensions in a modified presentation (indicated numerically: $150 \mathrm{~g} \mathrm{CO} 2$-equivalents per $100 \mathrm{~g}$ of product; company's commitment to reducing its greenhouse gas emissions by $10 \%$ per year), which results in an overall evaluation (Figure 1. group 4)

- CF indicated by a scale using traffic light color-coding (three-tier label: green (low), yellow (neutral), and red (high)) (Figure 1, group 5)

- CF indicated by a scale using traffic light color-coding (five-tier label: green, light green, yellow, orange, red) (Figure 1, group 6)

As this study used split sampling to differentiate between the different designs of carbon footprint labels, respondents from the first group saw the three common carbon footprint labels that were introduced by the Carbon Trust in 2001. Respondents from the second to sixth groups saw modifications of the familiar carbon footprint label. The participants were randomly allocated into groups.

The intention of this experiment was to analyze the impact of different carbon footprint designs on purchase decisions. To permit such comparisons, the choice-experiment had to be conducted in each of the six groups by estimating the importance of different attributes of tomatoes. The attributes (origin, price, organic label) are usually available at the POS in regular supermarkets. The climate label is established as an additional attribute that is currently not available at the POS. Table 1 presents the combination of the attributes and their specifications. 
Table 1. Attributes and their Specifications (Levels) used in the CBCA.

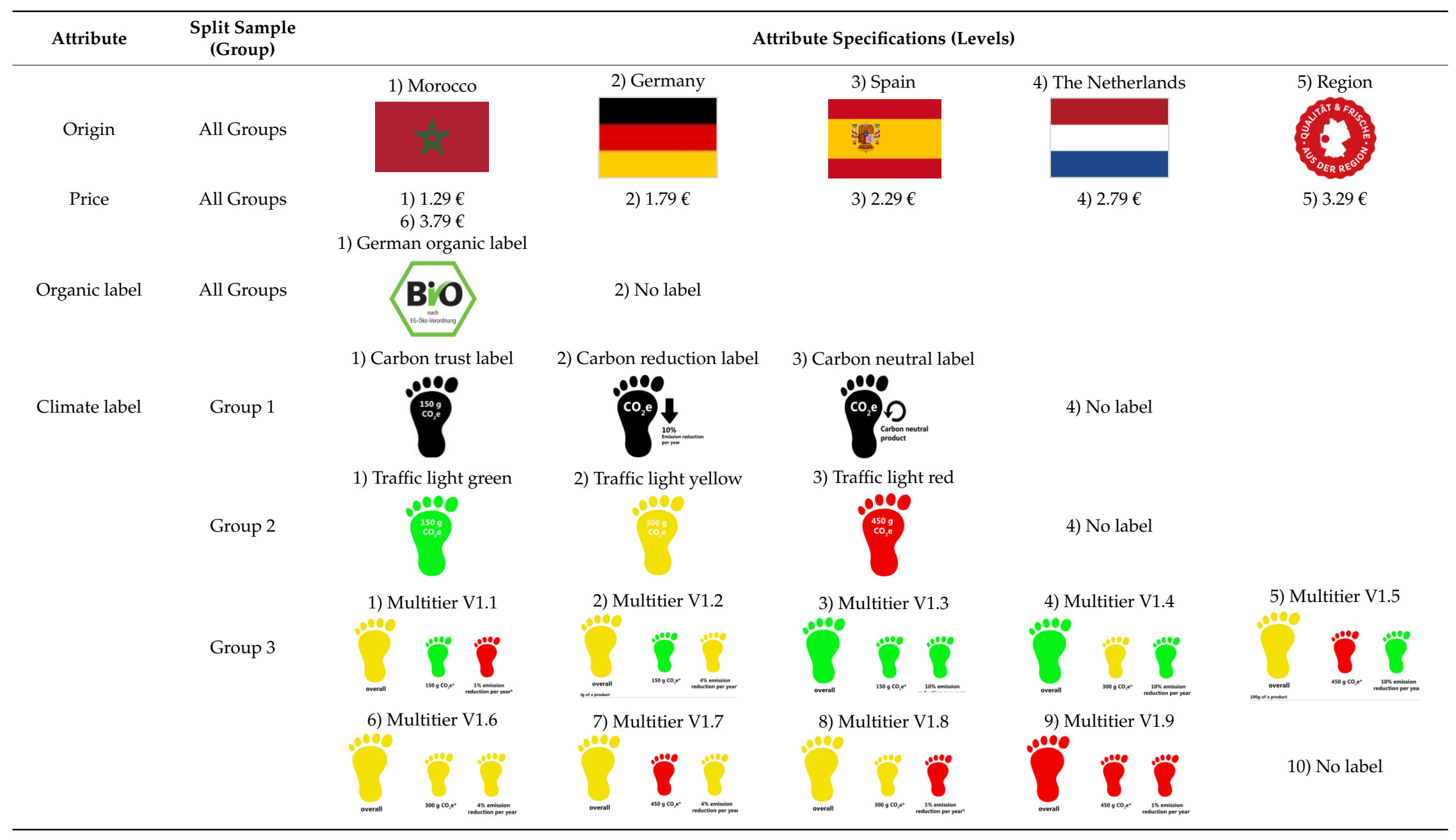


Table 1. Cont.

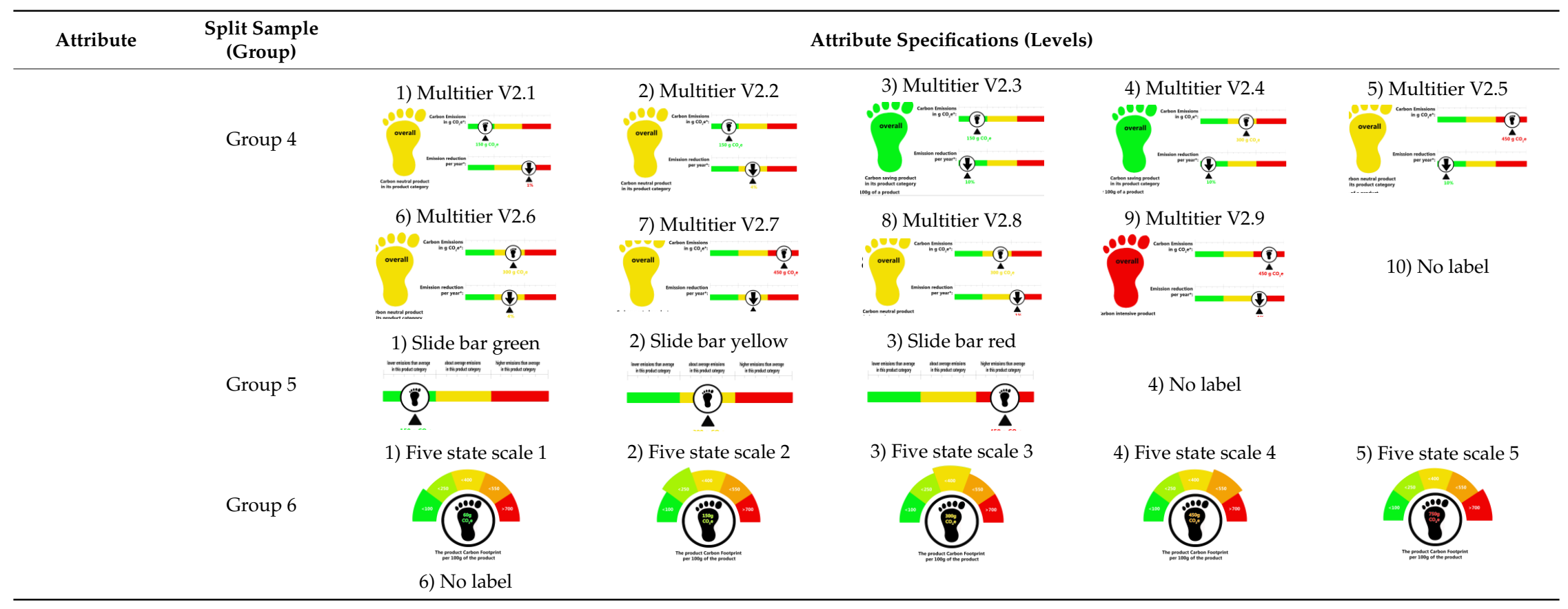


The most important European countries for exporting tomatoes to Germany are the Netherlands, followed by Spain and Morocco. The remaining shares were imported from Belgium, Italy, and non-European countries, and this study did not consider them. The German organic label is a state-controlled label and it is widely accepted among German consumers [34]. The range of the "price" attribute of tomatoes is based on AMI-Data (Agricultural Market-Information Organization) of 2010-2014 and on observations in supermarkets. The AMI prices varied between $1.85 € / \mathrm{kg}$ and $5.07 € / \mathrm{kg}$ [35].

The choice sets were operationalized with the query and statistical software Lighthouse Studio 9.5.2 from Sawtooth Software. Figure 2 shows one of the choice sets used, whereby the "no-choice"-option is missing in this figure.

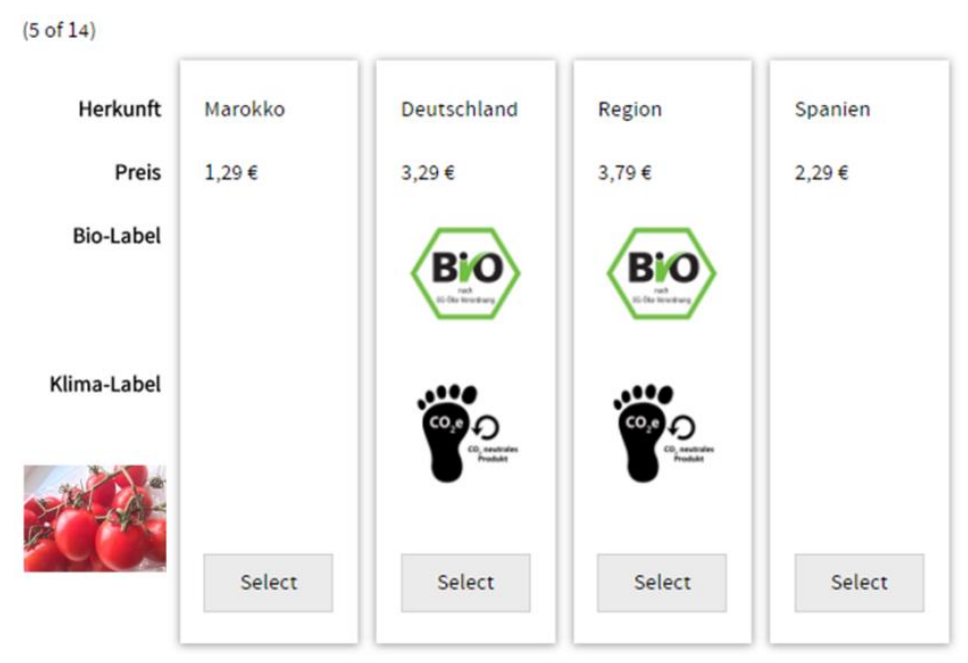

Figure 2. Example of a choice set used for the choice-based conjoint analysis (CBCA).

Hierarchical Bayes (HB) estimation approach is used to analyze the data. Lighthouse Studio includes a built-in HB estimation routine that estimates an HB model using a Monte Carlo Markov Chain algorithm [36]. Just like the latent class (LC) analysis, the HB approach uses the concept of conditional probabilities. However, while the LC method assumes that the subjects are subdivided into a defined set of different, homogeneous segments (latent classes), the HB approach starts from the premise that there is a continuous distribution of preferences, so that groups are not sharply delineated from each other.

\section{Results}

First, the sample is described. Subsequently, the results from the CBCA are presented to provide an understanding of the samples choice behavior. Furthermore, the findings of the latent class analysis, as well as the results of the CBCA, are shown, followed by the outcomes of the food-related lifestyles, label, and buying-related questions and the carbon footprint quiz. Finally, the previously analyzed influencing factors conduce to describe their effect on the relative importance of the CBCA attributes.

\subsection{Sample Description and Initial Questions}

Table 2 illustrates the socio-demographic characteristics for the examined sample, as well as for the German population in 2017. 
Table 2. Socio-demographic Characteristics of the Sample.

\begin{tabular}{|c|c|c|c|c|}
\hline Characteristic & $\begin{array}{l}\text { Characteristics } \\
\text { Specification }\end{array}$ & Frequency & Percent (\%) & $\begin{array}{l}\text { All German Households } \\
\text { in } 2017(\%) *\end{array}$ \\
\hline \multirow[t]{5}{*}{ Age (years) } & $16-29$ & 123 & 20.88 & 20.80 \\
\hline & $30-39$ & 109 & 18.51 & 14.00 \\
\hline & $40-49$ & 128 & 21.73 & 16.00 \\
\hline & $50-59$ & 130 & 22.07 & 18.20 \\
\hline & $60-69$ & 99 & 16.81 & 13.40 \\
\hline \multirow[t]{2}{*}{ Gender } & Female & 304 & 51.61 & 51.00 \\
\hline & Male & 285 & 48.39 & 49.00 \\
\hline \multirow[t]{2}{*}{ Place of residence } & Rural region & 229 & 38.88 & 41.00 \\
\hline & Urban region & 360 & 61.12 & 58.90 \\
\hline \multirow[t]{6}{*}{ Employment status } & $\begin{array}{l}\text { Full-time } \\
\text { employment }\end{array}$ & 244 & 41.54 & 40.00 \\
\hline & $\begin{array}{l}\text { Part-time } \\
\text { employment }\end{array}$ & 98 & 16.75 & 10.40 \\
\hline & In education/study & 18 & 3.17 & 2.50 \\
\hline & Student & 38 & 6.56 & 3.80 \\
\hline & Homemaker & 51 & 8.77 & 11.10 \\
\hline & Unemployed & 136 & 23.20 & 32.20 \\
\hline \multirow[t]{5}{*}{ Persons in household } & 1 & 191 & 32.54 & 23.80 \\
\hline & 2 & 220 & 37.46 & 38.10 \\
\hline & 3 & 85 & 14.54 & 17.20 \\
\hline & 4 & 61 & 10.47 & 15.60 \\
\hline & $\geq 5$ & 28 & 4.98 & 5.30 \\
\hline \multirow[t]{4}{*}{$\begin{array}{l}\text { Children in } \\
\text { household }\end{array}$} & 0 & 434 & 73.82 & 71.70 \\
\hline & 1 & 81 & 13.89 & 15.10 \\
\hline & 2 & 50 & 8.62 & 10.60 \\
\hline & $\geq 3$ & 20 & 3.66 & 2.60 \\
\hline \multirow{8}{*}{$\begin{array}{l}\text { Net household } \\
\text { income }\end{array}$} & $<500 €$ & 27 & 4.58 & 0.90 \\
\hline & $500-900 €$ & 52 & 8.83 & 8.10 \\
\hline & $900-1300 €$ & 88 & 14.94 & 11.20 \\
\hline & $1300-1700 €$ & 78 & 13.24 & 14.10 \\
\hline & $1700-2000 €$ & 57 & 9.68 & 7.00 \\
\hline & $2000-2600 €$ & 104 & 17.66 & 14.00 \\
\hline & $2600-4500 €$ & 148 & 25.13 & 29.80 \\
\hline & $<4500 €$ & 35 & 5.94 & 14.90 \\
\hline \multirow{4}{*}{$\begin{array}{c}\text { Amount of tomatoes } \\
\text { bought in the last } \\
2 \text { weeks }\end{array}$} & $<500 \mathrm{~g}$ & 212 & 35.99 & n.A. \\
\hline & $500-1000 \mathrm{~g}$ & 263 & 44.65 & n.A. \\
\hline & $1000-1500 \mathrm{~g}$ & 68 & 11.54 & n.A. \\
\hline & $>1500 \mathrm{~g}$ & 41 & 6.96 & n.A. \\
\hline \multirow[t]{4}{*}{ Purchase location ** } & Supermarket & 422 & 71.65 & n.A. \\
\hline & Discount shop & 333 & 56.54 & n.A. \\
\hline & Farmers' market & 134 & 22.75 & n.A. \\
\hline & Wholefood shop & 50 & 8.49 & n.A. \\
\hline
\end{tabular}

Note. * best for planning, 2017, ${ }^{* *}$ Multiple response, $N=589$.

The comparison of characteristics regarding the values of the study sample with the values of the German population reveals that the gender ratio is equivalent to the total population in Germany [37]. The age distribution is slightly overrepresented in the age categories of 30-39, 40-49, 50-59, and 60-69. The majority of the respondents reside in urban areas. Furthermore, $16.75 \%$ of participants were employed part-time and $6.56 \%$ were students at the time that the survey was conducted. This is high when compared to the German average of $10.4 \%$ in part-time employment and $3.8 \%$ students. On the other hand, unemployed persons are underrepresented in this study population. Lastly, the net income situation approximately reflects the German population. The socio-demographic distribution 
of the conducted survey is comparable for the most part with the general socio-demographic situation in Germany.

\subsection{Results of the Choice-Based Conjoint Analysis for the Whole Sample}

The part-worth utilities were calculated in order to investigate consumer preferences towards different designs of carbon footprint labels. Figures 3-8 present the part-worth utilities that result from the CBCA per group. The attribute specifications "Morocco", "3.79 $€$ ", and "no label" were defined as reference part-worth values and were therefore set to zero. As described earlier, it is not only the total value of the part-worth utilities that matter, but also the relative values between the reference attribute specification and the attribute part-worth utilities.

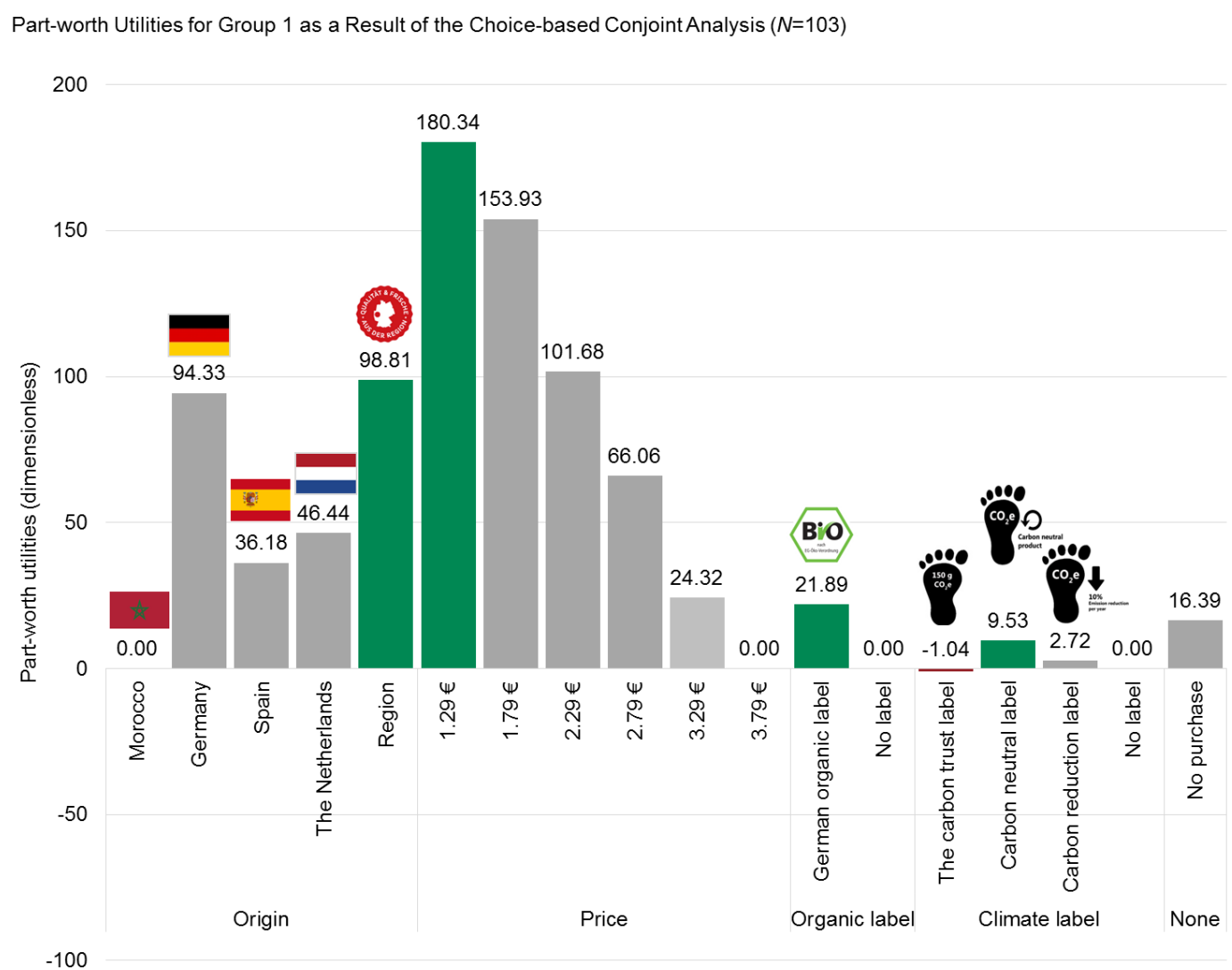

Figure 3. Resulting part-worth utilities of group 1 of the conducted CBCA-Attributes' importance from left to right: $29.51 \%, 49.67 \%, 10.06 \%$, and $10.77 \%$. 
Part-worth Utilities for Group 2 as a Result of the Choice-based Conjoint Analysis ( $N=102)$

200

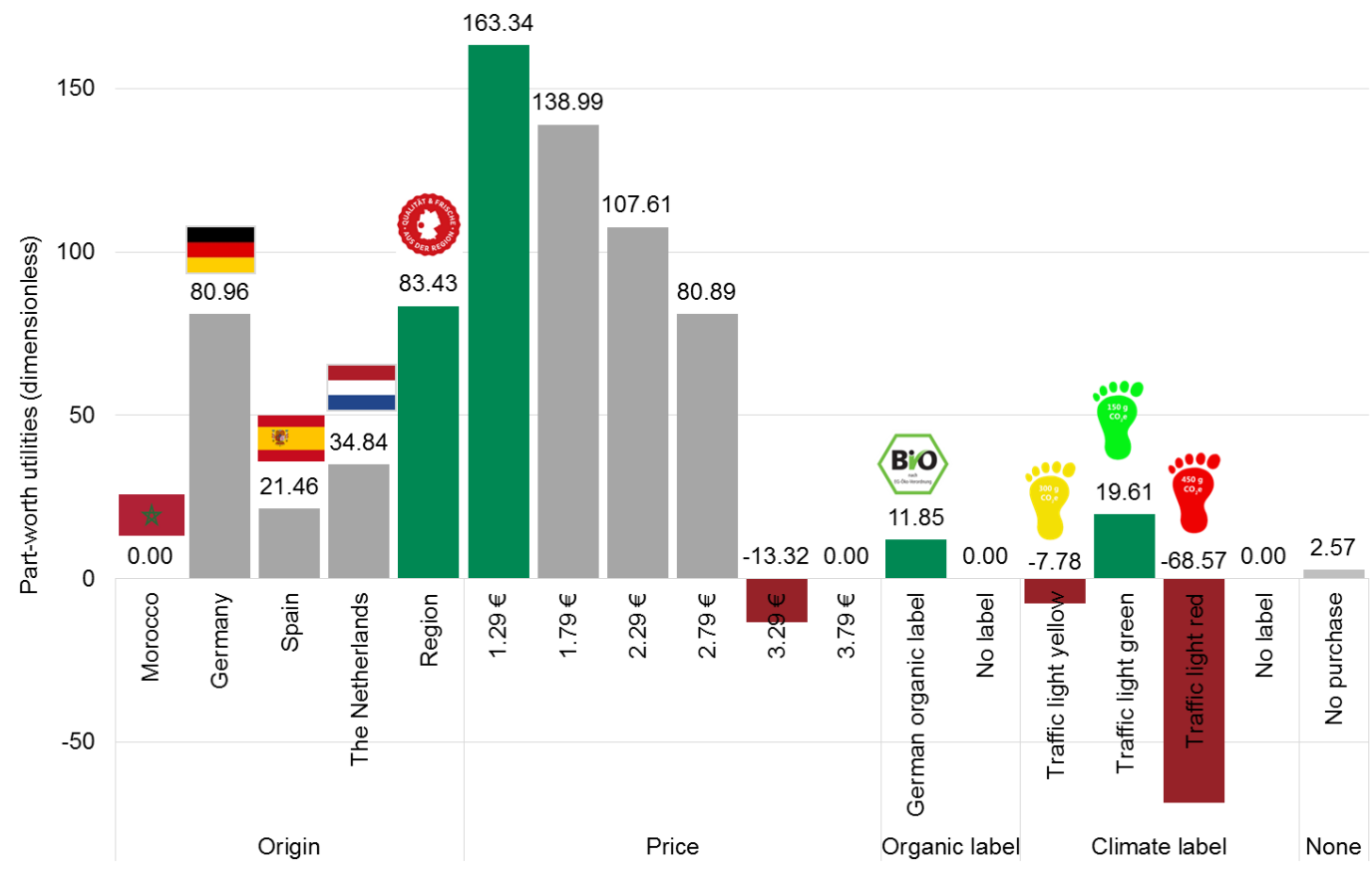

$-100$

Figure 4. Resulting part-worth utilities of group 2 of the conducted CBCA-Attributes' importance from left to right: $23.55 \%, 47.58 \%, 5.16 \%$, and $23.71 \%$.

Part-worth Utilities for Group 3 as a Result of the Choice-based Conjoint Analysis ( $N=100)$

200

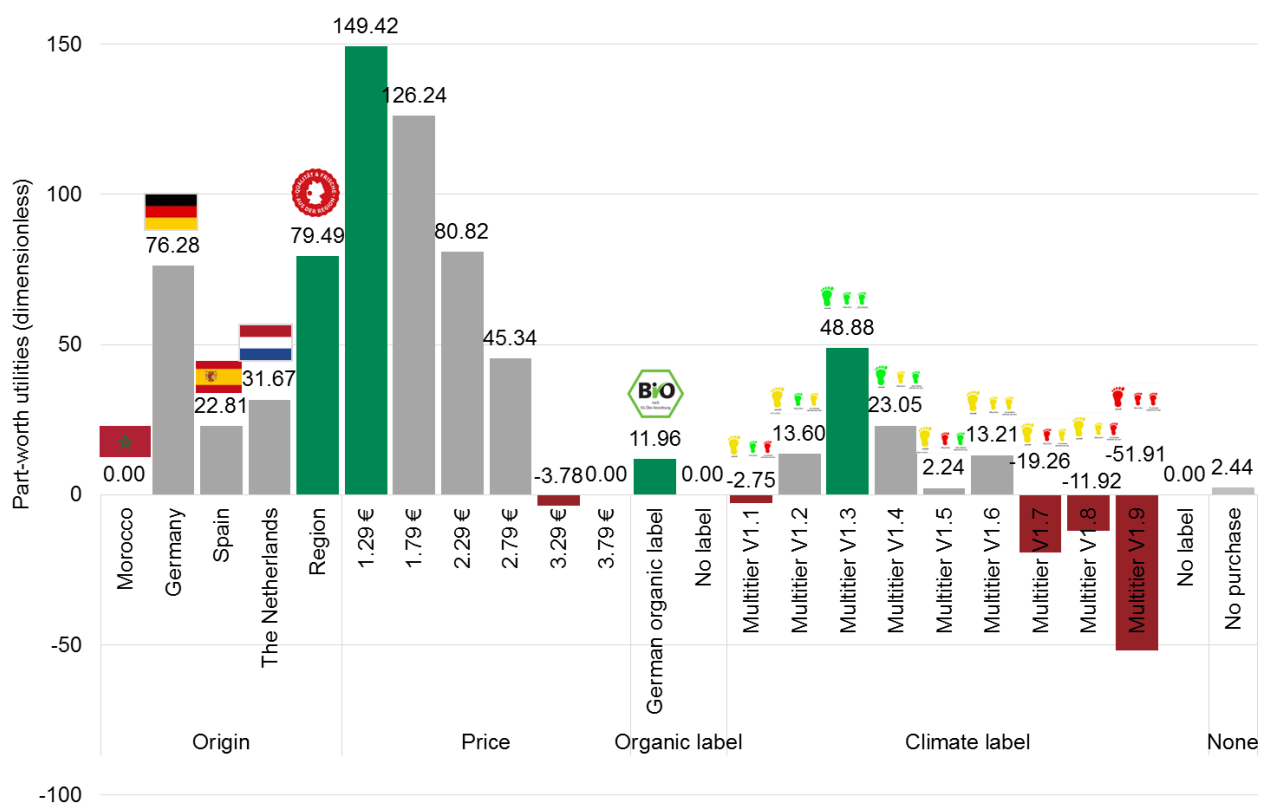

Figure 5. Resulting part-worth utilities of group 3 of the conducted CBCA-Attributes' importance from left to right: $23.66 \%, 41.19 \%, 8.78 \%$, and $26.37 \%$. 
Part-worth Utilities for Group 4 as a Result of the Choice-based Conjoint Analysis ( $N=91)$

200

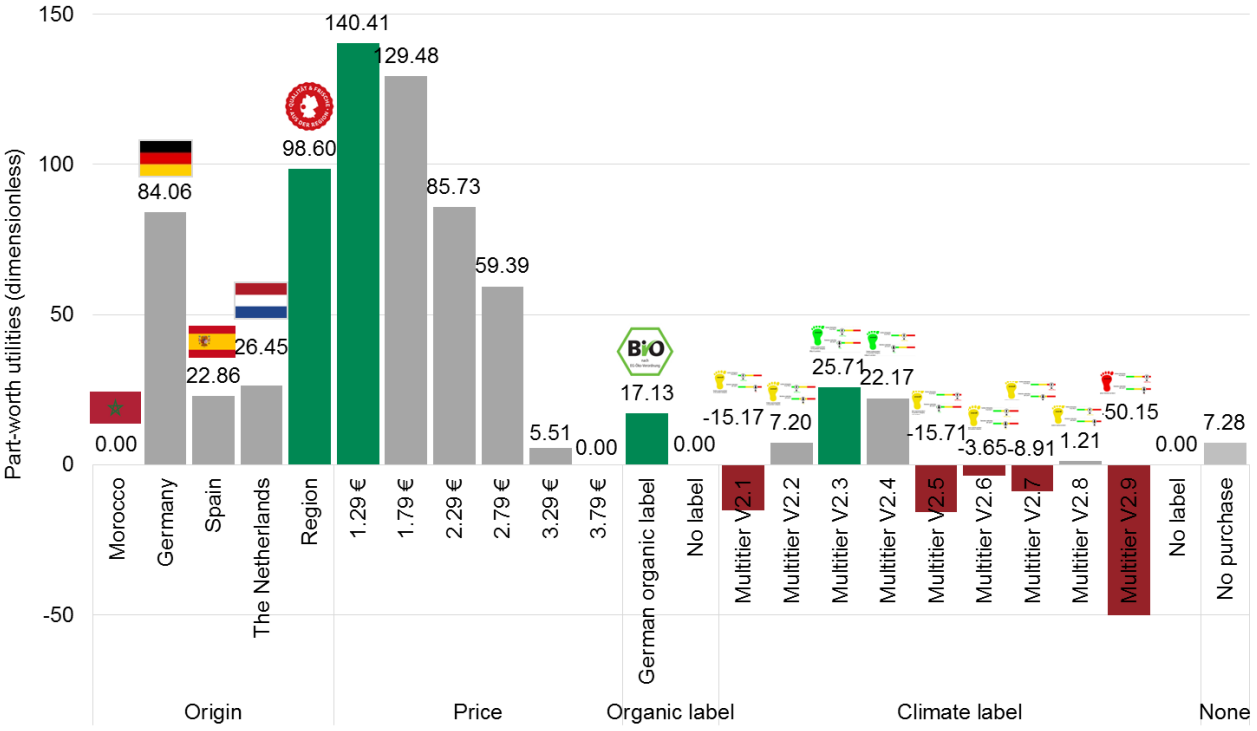

$-100$

Figure 6. Resulting part-worth utilities of group 4 of the conducted CBCA-Attributes' importance from left to right: $28.49 \%, 39.04 \%, 8.41 \%$, and $24.06 \%$.

Part-worth Utilities for Group 5 as a Result of the Choice-based Conjoint Analysis ( $N=99)$

200

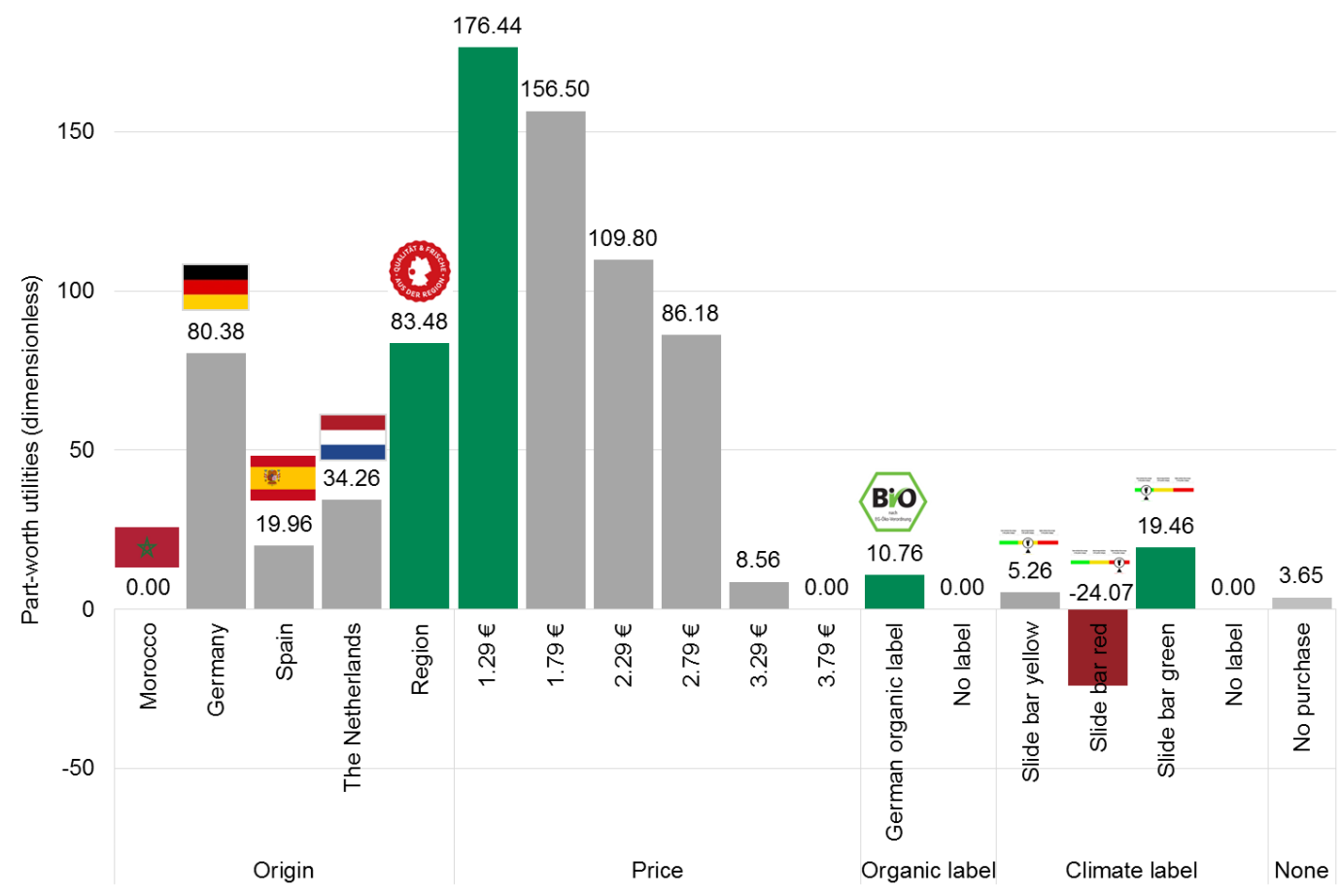

$-100$

Figure 7. Resulting part-worth utilities of group 5 of the conducted CBCA-Attributes' importance from left to right: $25.41 \%, 49.32 \%, 10.23 \%$, and $15.04 \%$. 
Part-worth Utilities for Group 6 as a Result of the Choice-based Conjoint Analysis $(N=103)$

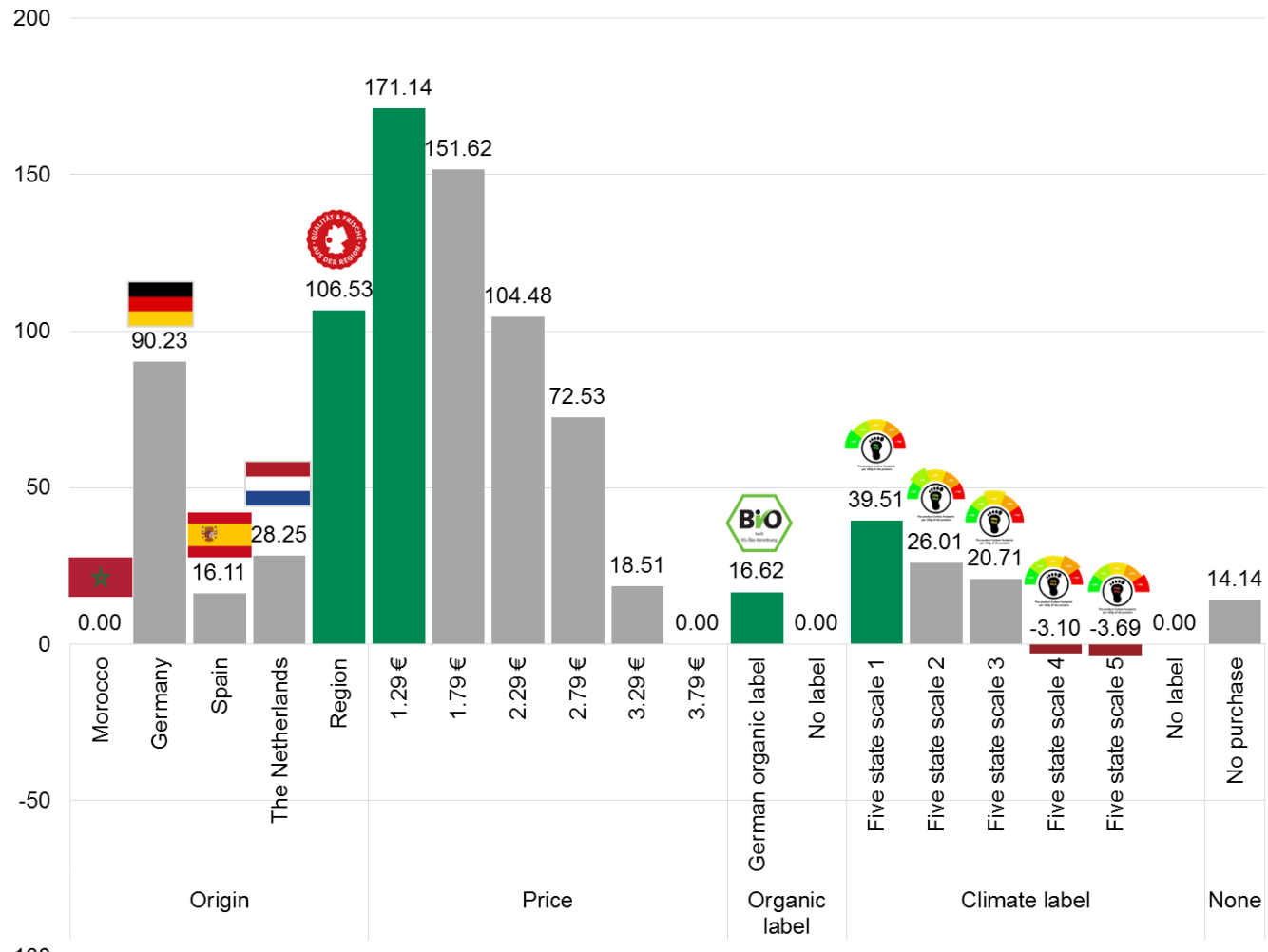

Figure 8. Resulting part-worth utilities of group 6 of the conducted CBCA-Attributes' importance from left to right: $29.73 \%, 45.40 \%, 7.27 \%$, and $17.60 \%$.

The findings for group $1(N=103)$ in Figure 3 indicate the highest part-worth utility for the price specifications " $1.29 €$ ", " $1.79 €$ ", and " $2.29 €$ ", followed by the domestically produced vine tomatoes with the specifications "region" and "Germany". Focusing on the attributes concerning the climate label-in the case of group 1, the carbon footprint label in its original three forms-the "carbon neutral label" and the "carbon reduction label" gain positive values, whereas the "the Carbon Trust label" shows a negative part-worth utility.

The characteristic price was accountable for $49.67 \%$ (relative importance) of the respondents' choice decisions, followed by the origin (29.51\%), climate label (10.77\%), and organic label $(10.06 \%)$.

The outcomes for group $2(N=102)$ show a similar picture (Figure 4$)$. The findings also indicate the highest part-worth utility values for the lowest price " $1.29 €$ " and are then followed by the increasing prices with decreasing part-worth utilities. The origin specifications "region" and "Germany" rank in position four and five. Label utilities for group 2 - the traffic light color-coded label by [2] - are categorized, as follows: "traffic light green", "traffic light yellow", and "traffic light red".

The relative importance of the choice characteristics for group 2 is slightly different. Price is-as is the case with group 1-the most important factor for the choice decisions (47.58\%). However, the relative importance of the climate label $(23.71 \%)$ outpaces the importance of the characteristic of origin (23.55\%), followed by the organic label $(5.16 \%)$.

The findings of group $3(N=100$, Figure 5$)$ show the same order for the first five positions as for group 2. Furthermore, the outcomes indicate the highest label utility value for "multitier V1.3". Another climate label specification "multitier V1.4" ranks in eighth position. The "German organic label" ranks in thirteenth position. Focusing on the attributes concerning the climate label-in the case of group 3, an extension of the traffic light labelling - it is noticeable that four specifications reflect negative part-worth utility values. The second highest price "3.29 $€$ " also shows a negative part-worth utility value. 
The relative importance of the choice characteristics for group 3 shows a similar picture as observed before for group 2. Price is the most important factor in the choice decisions $(41.19 \%)$. The price characteristic is followed by the climate label $(26.37 \%)$, then by origin $(23.66 \%)$, and lastly by the organic label $(8.78 \%)$.

The outcomes of group $4(N=91$, Figure 6$)$ show a slightly different order to group 3 . Furthermore, the outcomes indicate the highest label utility value for "multitier V2.3", followed by "multitier V2.4", and the "German organic label". Focusing on the attributes regarding the climate label-in the case of group 4, another extension of the traffic light labelling-it is noticeable that five out of nine label design specifications show negative part-worth utility values.

The relative importance of the choice characteristics for group 4 shows a different picture to those observed for group 2 and group 3. Price is still the most important factor for the choice decisions $(39.04 \%)$, but it is similar to the relative importance distribution of group 1 ; it is followed by the origin $(28.49 \%)$, then in position three by the climate label $(24.06 \%)$, and lastly by the organic label $(8.41 \%)$.

The findings for group $5(N=99$, Figure 7$)$ indicate the highest part-worth utility values for the price specifications, followed by the domestically produced tomatoes with the specifications "region" and "Germany". Subsequently, the climate label specification "slide bar green" is ranked next, followed by the "German organic label". Focusing on the remaining attributes concerning the climate label-in the case of group 5, the traffic light color-coding in the form of a slide bar-the "slide bar green" and the "slide bar yellow" gain positive part-worth utility values, whereas the "slide bar red" shows a negative part-worth utility.

The relative importance of the choice characteristics for group 5 shows a similar picture to that observed before for group 1 and group 4 . The characteristic price was accountable for $49.32 \%$ (relative importance) of the respondents' choice decisions, followed by the origin (25.41\%), climate label (15.04\%), and organic label (10.23\%).

Lastly, group $6(N=103$, Figure 8$)$ shows the familiar image of decreasing part-worth utility values with an increasing price level. Focusing on the attributes regarding origin, the domestically produced vine tomatoes show the highest part-worth utilities. Furthermore, the climate label specifications show a similar pattern to the price characteristic: with increasing indication of greenhouse gas pollution, decreasing part-worth utility values are observed. Three out of five show positive values; "five-point scale 4 " as well as "five-point scale 5 " have negative part-worth utilities.

The relative importance of the choice characteristics for group 6 shows an unaffected order of the decision-making factors, being similar to group 1 , group 4 , and group 5 . Price is still the most important factor in the choice decisions $(45.40 \%)$. It is followed by the origin $(29.73 \%)$, then in position three by the climate label (17.60\%), and lastly by the organic label $(7.27 \%)$.

In Figure 9, the results of the relative importance of the choice characteristics are presented for every group. 
Relative Importances (\%) of the Attributes per Group

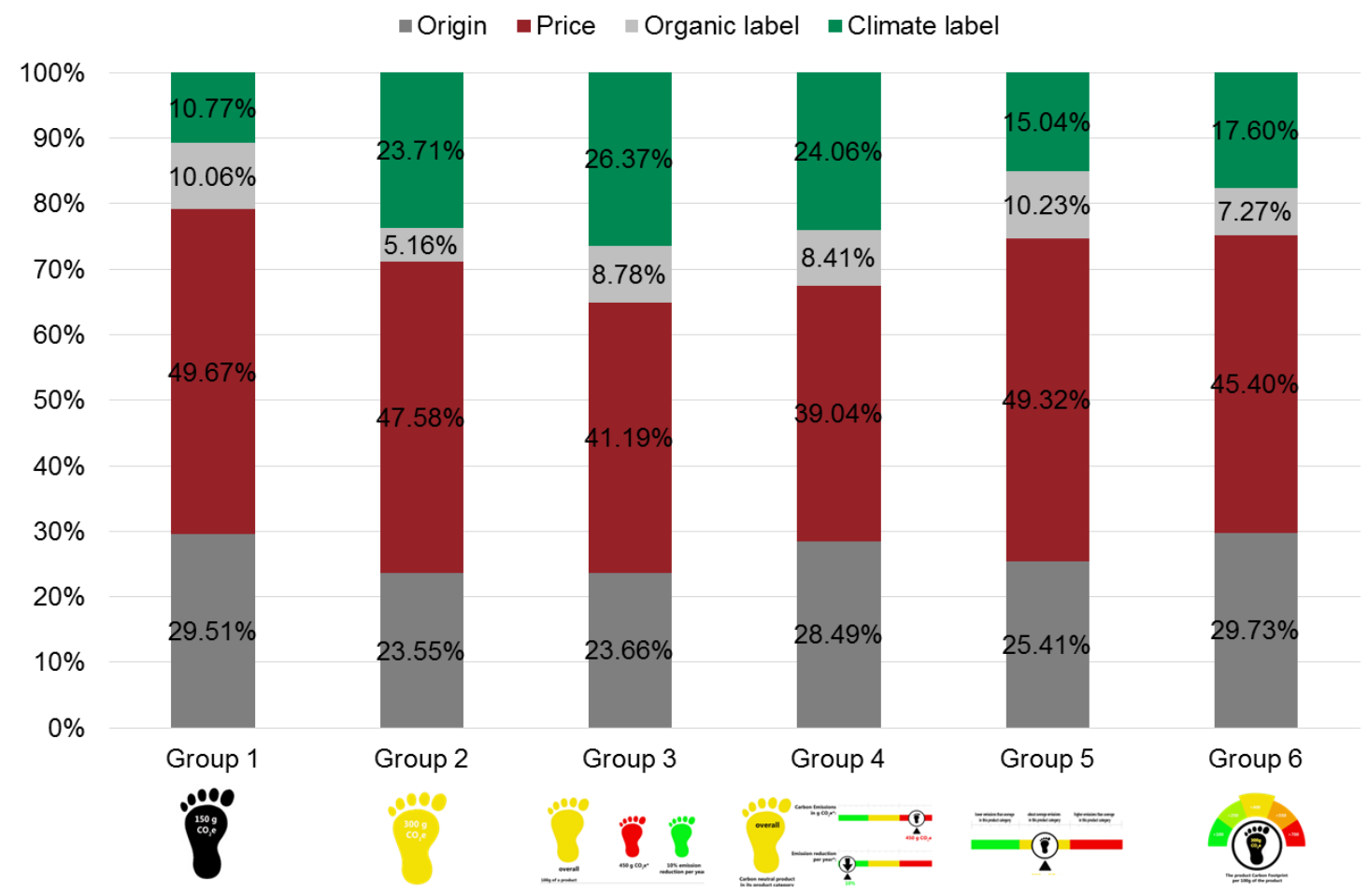

Figure 9. Relative attribute importance for all six groups-Sample size of the groups from left to right $N=103, N=102, N=100, N=91, N=99, N=103$.

As can be seen in Figure 9, the carbon footprint label characteristic received the highest relative importance in the cases of group 3, followed by group 4, and group 2, with all viewed as being relatively easy to understand quality labels.

\subsection{Results of the Latent Class Analysis}

To select the proper number of classes (segments), Table 3 illustrates the findings of a two-class model run up to a five-class model run for each of the six groups. To identify the optimal solution, information regarding the model fit (including log likelihood, Akaike information criterion (AIC), consistent AIC (CAIC), Bayesian information criterion (BIC), and average membership) has to be compared. To date, the selection of the best criterion to decide on the number of classes is still inconclusive. There are a variety of studies examining the best indicator for deciding on the number of classes [38-40]. A large number of studies suggest that the BIC is the best indicator for class enumeration, because it identifies the number of classes the most consistently across models. To assure practical relevance, it is advised to not only rely on statistical data, but also consider the interpretability as well as stability of the solutions [36]. Furthermore, the limitations of the IC indexes should be taken into account. 
Table 3. Model Selection for Latent class Segmentation for all Six Groups.

\begin{tabular}{|c|c|c|c|c|c|}
\hline \multicolumn{6}{|c|}{ Carbon Trust/Neutral/Reduction Label (Group 1) } \\
\hline Classes & Log-likelihood & AIC & CAIC & $\mathrm{BIC}$ & Average max. membership \\
\hline 2 & -1296.43 & 2650.86 & 2828.24 & 2799.24 & 0.976 \\
\hline 3 & -1235.10 & 2558.19 & 2827.31 & 2783.31 & 0.981 \\
\hline 4 & -1173.78 & 2465.56 & 2826.43 & 2767.43 & 0.982 \\
\hline 5 & -1140.77 & 2429.54 & 2882.16 & 2808.16 & 0.975 \\
\hline \multicolumn{6}{|c|}{ Traffic light green (group 2) } \\
\hline Classes & Log-likelihood & AIC & CAIC & $\mathrm{BIC}$ & Average max. membership \\
\hline 2 & -1235.04 & 2528.08 & 2705.27 & 2676.27 & 0.973 \\
\hline 3 & -1135.10 & 2358.20 & 2627.04 & 2583.04 & 0.979 \\
\hline 4 & -1073.08 & 2264.16 & 2624.65 & 2565.65 & 0.973 \\
\hline 5 & -1043.62 & 2235.23 & 2687.37 & 2613.37 & 0.955 \\
\hline \multicolumn{6}{|c|}{ Multitier V1 (group 3) } \\
\hline Classes & Log-likelihood & AIC & CAIC & $\mathrm{BIC}$ & Average max. membership \\
\hline 2 & -1173.46 & 2428.93 & 2678.00 & 2637.00 & 0.954 \\
\hline 3 & -1103.37 & 2330.75 & 2707.40 & 2645.40 & 0.966 \\
\hline 4 & -1042.63 & 2251.26 & 2755.48 & 2672.48 & 0.962 \\
\hline 5 & -997.58 & 2203.17 & 2834.97 & 2730.97 & 0.982 \\
\hline \multicolumn{6}{|c|}{ Multitier V2 (group 4) } \\
\hline Classes & Log-likelihood & AIC & CAIC & $\mathrm{BIC}$ & Average max. membership \\
\hline 2 & -1126.14 & 2334.29 & 2579.66 & 2538.66 & 0.958 \\
\hline 3 & -1039.67 & 2203.35 & 2574.40 & 2512.40 & 0.984 \\
\hline 4 & -988.90 & 2143.81 & 2640.54 & 2557.54 & 0.985 \\
\hline 5 & -956.55 & 2121.11 & 2743.52 & 2639.52 & 0.979 \\
\hline \multicolumn{6}{|c|}{ Slide bar (group 5) } \\
\hline Classes & Log-likelihood & AIC & CAIC & BIC & Average max. membership \\
\hline 2 & -1250.66 & 2559.31 & 2735.61 & 2706.61 & 0.963 \\
\hline 3 & -1175.68 & 2439.37 & 2706.85 & 2662.85 & 0.966 \\
\hline 4 & -1107.20 & 2332.40 & 2691.07 & 2632.07 & 0.972 \\
\hline 5 & -1067.78 & 2283.56 & 2733.42 & 2659.42 & 0.968 \\
\hline \multicolumn{6}{|c|}{ Five-point scale (group 6) } \\
\hline Classes & Log-likelihood & AIC & CAIC & $\mathrm{BIC}$ & Average max. membership \\
\hline 2 & -1197.58 & 2461.16 & 2663.03 & 2630.03 & 0.983 \\
\hline 3 & -1138.07 & 2376.13 & 2681.99 & 2631.99 & 0.968 \\
\hline 4 & -1088.37 & 2310.74 & 2720.59 & 2653.59 & 0.974 \\
\hline 5 & -1053.92 & 2275.84 & 2789.68 & 2705.68 & 0.980 \\
\hline
\end{tabular}

In the present study, the AIC declines considerably up to the five-class model for each of the six split samples. Whereas, CAIC and BIC show the same pattern across all of the samples. For group 1 , group 2, and group 5, CAIC and BIC decline up to the four-class solution, and then show an increase for the five-class model. For all other groups $(3,4$, and 6$)$, it can be observed that the decline lasts only until the three-class solution, and afterwards the values rebound until the five-class model (Table 3 ). Nevertheless, while considering the limitations and practical relevance, the four-class model seems to be the best solution across all six groups in this study.

Table 4 illustrates the part-worth utilities of the different attributes for every class (segment) and all six groups. The segmentation clearly demonstrates the heterogeneity of the underlying utility functions of the segments within the six groups. Each of the segments show a distinct concentration of the part-worth utility values regarding the attributes and their specifications. 
Table 4. Part-worth Utilities of the Different Attributes for every Segment and all Six Groups.

\begin{tabular}{|c|c|c|c|c|c|c|c|c|c|c|c|c|c|c|}
\hline \multicolumn{5}{|c|}{ Carbon Trust/Neutral/Reduction Label (Group 1) } & \multicolumn{5}{|c|}{ Traffic Light Green (Group 2) } & \multicolumn{5}{|c|}{ Slide Bar (Group 5) } \\
\hline & $\mathrm{S} 1$ & S2 & S3 & $\mathrm{S} 4$ & & $\mathrm{~S} 1$ & S2 & S3 3 & $\mathrm{~S} 4$ & & S1 & S2 & S 3 & $\mathrm{~S} 4$ \\
\hline Part-worth utilities & $9.8 \%$ & $20.6 \%$ & $22.5 \%$ & $47.2 \%$ & Part-worth utilities & $23.4 \%$ & $26.5 \%$ & $13.5 \%$ & $36.6 \%$ & Part-worth utilities & $18.7 \%$ & $41.5 \%$ & $16.1 \%$ & $23.7 \%$ \\
\hline Morocco & 0 & 0 & 0 & 0 & Morocco & 0 & 0 & 0 & 0 & Morocco & 0 & 0 & 0 & 0 \\
\hline Germany & -45 & 288 & 107 & 44 & Germany & 155 & 124 & 12 & 18 & Germany & 122 & 31 & 142 & 35 \\
\hline Spain & -26 & 60 & 80 & 21 & Spain & -10 & 52 & 11 & 8 & Spain & 32 & 3 & 12 & 10 \\
\hline The Netherlands & -41 & 177 & 57 & 22 & The Netherlands & 37 & 80 & 4 & 8 & The Netherlands & 63 & 17 & -1 & 20 \\
\hline Region & -11 & 299 & 100 & 41 & Region & 170 & 132 & 12 & 15 & Region & 67 & 46 & 134 & 40 \\
\hline $1.29 €$ & 213 & 50 & 124 & 175 & $1.29 €$ & 2 & 117 & 351 & 81 & $1.29 €$ & 62 & 301 & -5 & 342 \\
\hline $1.79 €$ & 202 & 37 & 112 & 148 & $1.79 €$ & 15 & 110 & 319 & 70 & $1.79 €$ & 62 & 287 & 29 & 308 \\
\hline $2.29 €$ & 149 & 40 & 100 & 97 & $2.29 €$ & 12 & 101 & 291 & 54 & $2.29 €$ & 75 & 256 & 1 & 256 \\
\hline $2.79 €$ & 141 & 36 & 73 & 65 & $2.79 €$ & 13 & 82 & 277 & 42 & $2.79 €$ & 18 & 228 & 18 & 253 \\
\hline $3.29 €$ & 111 & -18 & 61 & -162 & $3.29 €$ & -35 & 13 & 102 & -286 & $3.29 €$ & -74 & 178 & -37 & 11 \\
\hline $3.79 €$ & 0 & 0 & 0 & 0 & $3.79 €$ & 0 & 0 & 0 & 0 & $3.79 €$ & 0 & 0 & 0 & 0 \\
\hline German organic label & -76 & -3 & 116 & 11 & German organic label & 15 & 35 & -11 & 0 & German organic label & -58 & 24 & 75 & -10 \\
\hline No label & 0 & 0 & 0 & 0 & No label & 0 & 0 & 0 & 0 & No label & 0 & 0 & 0 & 0 \\
\hline The carbon trust label & -19 & 6 & 21 & -8 & Traffic light yellow & -8 & 11 & -8 & -4 & Slide bar yellow & -23 & 7 & 14 & 7 \\
\hline Carb. neutral label & -55 & 20 & 53 & 0 & Traffic light green & 76 & 29 & 5 & -1 & Slide bar red & -52 & -18 & -44 & 2 \\
\hline Carb. reduction label & -66 & 30 & 31 & -4 & Traffic light red & -79 & -86 & -21 & -15 & Slide bar green & 19 & 11 & 70 & -1 \\
\hline No label & 0 & 0 & 0 & 0 & No label & 0 & 0 & 0 & 0 & No label & 0 & 0 & 0 & 0 \\
\hline \multicolumn{5}{|c|}{ Multitier V1 (group 3) } & \multicolumn{5}{|c|}{ Multitier V2 (group 4) } & \multicolumn{5}{|c|}{ Five-point scale (group 6) } \\
\hline & $\mathrm{S} 1$ & S2 & S3 & S 4 & & S 1 & $\mathrm{~S} 2$ & S3 & S 4 & & S1 & $\mathrm{s} 2$ & S 3 & $\mathrm{~S} 4$ \\
\hline Part-worth utilities & $23.9 \%$ & $35.5 \%$ & $30.6 \%$ & $10.0 \%$ & Part-worth utilities & $15.3 \%$ & $38.4 \%$ & $25.7 \%$ & $20.6 \%$ & Part-worth utilities & $31.5 \%$ & $39.1 \%$ & $23.1 \%$ & $6.4 \%$ \\
\hline Morocco & 0 & 0 & 0 & 0 & Morocco & 0 & 0 & 0 & 0 & Morocco & 0 & 0 & 0 & 0 \\
\hline Germany & 157 & 16 & 86 & 29 & Germany & 250 & 35 & 164 & 18 & Germany & 187 & 32 & 74 & 43 \\
\hline Spain & 19 & -1 & 26 & 5 & Spain & 160 & 25 & 20 & 11 & Spain & 26 & 16 & 19 & -88 \\
\hline The Netherlands & 6 & 5 & 45 & 30 & The Netherlands & 182 & 22 & 13 & 45 & The Netherlands & 65 & 16 & 24 & -40 \\
\hline Region & 155 & 14 & 105 & -37 & Region & 228 & 69 & 190 & 39 & Region & 202 & 52 & 87 & 12 \\
\hline $1.29 €$ & 57 & 363 & 119 & 86 & $1.29 €$ & 91 & 239 & 78 & 54 & $1.29 €$ & 99 & 320 & 116 & 103 \\
\hline $1.79 €$ & 34 & 350 & 123 & 43 & $1.79 €$ & 104 & 205 & 78 & 47 & $1.79 €$ & 115 & 278 & 105 & 62 \\
\hline $2.29 €$ & 42 & 319 & 82 & 53 & $2.29 €$ & 64 & 128 & 101 & 19 & $2.29 €$ & 98 & 216 & 83 & 65 \\
\hline $2.79 €$ & 28 & 300 & 63 & 19 & $2.79 €$ & 41 & 86 & 74 & 18 & $2.79 €$ & 57 & 176 & 69 & 83 \\
\hline $3.29 €$ & -18 & 267 & 1 & 30 & $3.29 €$ & 17 & -38 & 37 & -46 & $3.29 €$ & 16 & 122 & -14 & 91 \\
\hline $3.79 €$ & 0 & 0 & 0 & 0 & $3.79 €$ & 0 & 0 & 0 & 0 & $3.79 €$ & 0 & 0 & 0 & 0 \\
\hline German organic label & 31 & -5 & 47 & -45 & German organic label & -3 & 7 & 2 & 70 & German organic label & 44 & 5 & 36 & -73 \\
\hline No label & 0 & 0 & 0 & 0 & No label & 0 & 0 & 0 & 0 & No label & 0 & 0 & 0 & 0 \\
\hline Multitier V1.1 & 17 & -3 & -7 & 51 & Multitier V2.1 & -8 & 1 & -47 & 25 & Five state scale 1 & 34 & 8 & 110 & -19 \\
\hline Multitier V1.2 & 25 & -7 & 23 & 68 & Multitier V2.2 & 36 & 12 & -19 & 31 & Five state scale 2 & 38 & 3 & 76 & -47 \\
\hline Multitier V1.3 & 87 & 3 & 56 & 169 & Multitier V2.3 & 7 & 18 & 8 & 118 & Five state scale 3 & 38 & 1 & 32 & -25 \\
\hline Multitier V1.4 & 64 & -7 & 28 & 149 & Multitier V2.4 & 35 & 6 & -10 & 123 & Five state scale 4 & 7 & -15 & 6 & -92 \\
\hline Multitier V1.5 & -10 & 1 & -1 & 78 & Multitier V2.5 & 13 & -8 & -26 & -18 & Five state scale 5 & 15 & -5 & -36 & -72 \\
\hline Multitier V1.6 & 10 & 0 & 4 & 131 & Multitier V2.6 & 20 & -24 & 11 & 53 & No label & 0 & 0 & 0 & 0 \\
\hline Multitier V1.7 & -8 & -12 & -28 & 27 & Multitier V2.7 & 15 & -8 & -37 & 27 & & & & & \\
\hline Multitier V1.8 & -32 & -8 & -16 & 105 & Multitier V2.8 & 30 & -6 & -50 & 31 & & & & & \\
\hline Multitier V1.9 & -50 & -13 & -69 & -34 & Multitier V2.9 & 1 & -29 & -97 & -62 & & & & & \\
\hline No label & 0 & 0 & 0 & 0 & No label & 0 & 0 & 0 & 0 & & & & & \\
\hline
\end{tabular}


Table 5 illustrates the relative attribute importance for the segments and groups and it underlines the findings that were described earlier in this chapter.

Table 5. Relative Attribute Importance for all Segments and all Groups.

\begin{tabular}{|c|c|c|c|c|}
\hline \multicolumn{5}{|c|}{ Carbon Trust/Neutral/Reduction Label (Group 1) } \\
\hline & $\mathrm{S} 1$ & S 2 & S 3 & S 4 \\
\hline $\begin{array}{c}\text { Attribute } \\
\text { Importances }\end{array}$ & $9.8 \%$ & $20.6 \%$ & $22.5 \%$ & $47.2 \%$ \\
\hline Origin & 11.28 & 74.81 & 26.87 & 11.07 \\
\hline Price & 53.17 & 16.93 & 30.95 & 84.17 \\
\hline Organic label & 19.08 & 0.65 & 28.94 & 2.70 \\
\hline Climate label & 16.47 & 7.61 & 13.24 & 2.05 \\
\hline \multicolumn{5}{|c|}{ Traffic light green (group 2) } \\
\hline & S 1 & S 2 & S3 & S 4 \\
\hline $\begin{array}{c}\text { Attribute } \\
\text { Importances }\end{array}$ & $23.4 \%$ & $26.5 \%$ & $13.5 \%$ & $36.6 \%$ \\
\hline Origin & 45.10 & 32.97 & 2.96 & 4.43 \\
\hline Price & 12.50 & 29.28 & 87.72 & 91.62 \\
\hline Organic label & 3.69 & 8.82 & 2.74 & 0.08 \\
\hline Climate label & 38.70 & 28.93 & 6.58 & 3.87 \\
\hline \multicolumn{5}{|c|}{ Multitier V1 (group 3) } \\
\hline & S 1 & S 2 & S 3 & S 4 \\
\hline $\begin{array}{c}\text { Attribute } \\
\text { Importances }\end{array}$ & $23.9 \%$ & $35.5 \%$ & $30.6 \%$ & $10.0 \%$ \\
\hline Origin & 39.23 & 4.17 & 26.25 & 16.73 \\
\hline Price & 18.68 & 90.84 & 30.64 & 21.42 \\
\hline Organic label & 7.78 & 1.16 & 11.87 & 11.21 \\
\hline Climate label & 34.30 & 3.84 & 31.23 & 50.64 \\
\hline \multicolumn{5}{|c|}{ Multitier V2 (group 4) } \\
\hline & S 1 & S 2 & S 3 & $\mathrm{~S} 4$ \\
\hline $\begin{array}{c}\text { Attribute } \\
\text { Importances }\end{array}$ & $15.3 \%$ & $38.4 \%$ & $25.7 \%$ & $20.6 \%$ \\
\hline Origin & 62.43 & 17.35 & 47.39 & 11.31 \\
\hline Price & 25.90 & 69.20 & 25.23 & 25.01 \\
\hline Organic label & 0.77 & 1.85 & 0.56 & 17.41 \\
\hline Climate label & 10.90 & 11.61 & 26.81 & 46.28 \\
\hline \multicolumn{5}{|c|}{ Slide bar (group 5) } \\
\hline & S 1 & S 2 & S 3 & S 4 \\
\hline $\begin{array}{c}\text { Attribute } \\
\text { Importances }\end{array}$ & $18.7 \%$ & $41.5 \%$ & $16.1 \%$ & $23.7 \%$ \\
\hline Origin & 30.49 & 11.54 & 35.87 & 9.99 \\
\hline Price & 37.34 & 75.24 & 16.62 & 85.54 \\
\hline Organic label & 14.40 & 5.97 & 18.83 & 2.39 \\
\hline Climate label & 17.78 & 7.24 & 28.68 & 2.08 \\
\hline \multicolumn{5}{|c|}{ Five-point scale (group 6) } \\
\hline & S 1 & S 2 & S3 & S 4 \\
\hline $\begin{array}{c}\text { Attribute } \\
\text { Importances }\end{array}$ & $31.5 \%$ & $39.1 \%$ & $23.1 \%$ & $6.4 \%$ \\
\hline Origin & 50.58 & 13.04 & 21.76 & 32.80 \\
\hline Price & 28.86 & 79.91 & 32.55 & 25.83 \\
\hline Organic label & 10.94 & 1.14 & 9.12 & 18.37 \\
\hline Climate label & 9.62 & 5.91 & 36.58 & 22.99 \\
\hline
\end{tabular}

The allocation of the attribute importance very well reflects the different emphasis of the part-worth utility values for the attribute specifications. In cases where the part-worth utilities were pronounced, particularly positive or negative the attributes gain more importance. A good example of this is the attribute price for group 1 for segments 1 and 4 . This results in a relative price attribute importance for segment 1 of $53.17 \%$ and for segment 4 of $84.17 \%$. These values do not only consider 
the specific manifestation of the attribute price, but they are also affected by the part-worth utility level of the remaining attributes.

\subsection{Results of the Direct Questions towards Characteristics Importance}

Figure 10 displays the results of the stated preference task following the general statement: "When buying vine tomatoes, it is important to me that ..." .

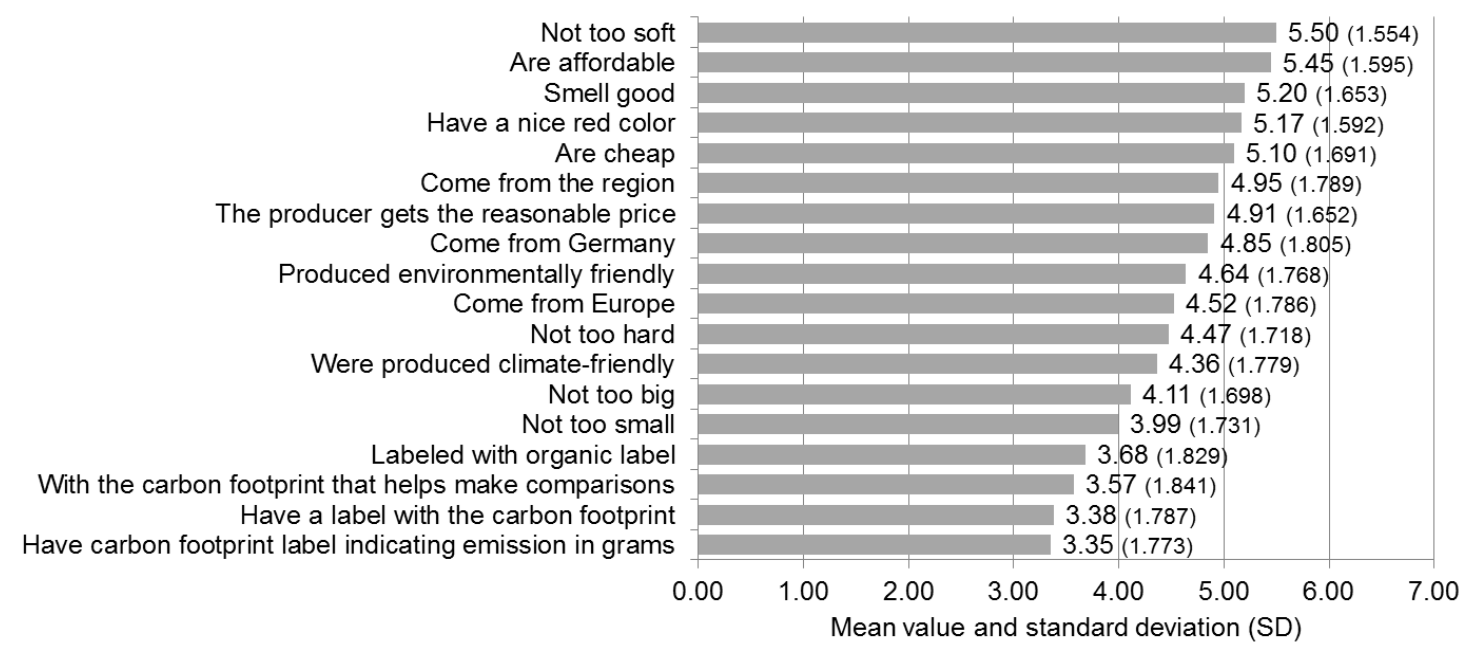

Figure 10. Results of the direct questions regarding characteristics' importance-Scale from 1 "not important at all" to 7 "very important", $N=587$.

The results show conformity with the findings of the $\mathrm{CBCA}$, displaying the high preference for affordable tomatoes. Additionally, regional and domestic production are top ranked and of high relevance for the interviewed consumers. Environmentally friendly production and a reasonable price for the producer also show high importance. Hence, food labelling attributes, such as labelling with an organic label, and especially carbon footprint labelling, were rated as comparably low in consumers' preferences in this task. Results of the CBCA for group 1, group 4, group 5, and group 6 confirmed the latter point. The results of group 2 and group 3 show a different picture due to the relatively high relative importance of the climate label—the second main factor after price-in terms of consumer decision-making (Figure 9).

\subsection{Results of the Factor Analysis for Food-Related Lifestyle and Label and Buying-Related Items}

Table 6 presents the statements, factors, and reliability coefficients for food-related lifestyles. According to the results of the factor analysis, the food-related lifestyle elements can be divided into five factors. 
Table 6. Factor Analysis Food-related Lifestyles.

\begin{tabular}{|c|c|c|c|}
\hline Factors and the Corresponding Variables & Mean & SD & Factor Loading \\
\hline \multicolumn{4}{|l|}{ Quality aspects (Cronbach's alpha: 0.896) } \\
\hline I prefer to buy food from my region & 5.30 & 1.636 & 0.802 \\
\hline $\begin{array}{l}\text { For me, the naturalness of the food is an } \\
\text { important factor }\end{array}$ & 5.36 & 1.552 & 0.791 \\
\hline $\begin{array}{l}\text { I prefer food with a trustworthy character (for } \\
\text { example, organic, Fairtrade, animal welfare) }\end{array}$ & 4.53 & 1.860 & 0.760 \\
\hline $\begin{array}{l}\text { I prefer to buy foods that were traditionally } \\
\text { made }\end{array}$ & 4.99 & 1.544 & 0.758 \\
\hline $\begin{array}{l}\text { I like to buy foods that have been hand-crafted } \\
\text { production }\end{array}$ & 4.50 & 1.695 & 0.728 \\
\hline I prefer fresh products to canned products & 5.62 & 1.470 & 0.705 \\
\hline $\begin{array}{l}\text { I would like to pay more money for animal } \\
\text { welfare approved meat and eggs }\end{array}$ & 4.69 & 1.891 & 0.696 \\
\hline \multicolumn{4}{|l|}{ Attending culinary events (Cronbach's alpha: } \\
\hline I like to read food blogs on the Internet & 2.83 & 1.914 & 0.774 \\
\hline I like to visit food fairs & 2.81 & 1.905 & 0.768 \\
\hline $\begin{array}{l}\text { I like to buy food in specialty shops, where I } \\
\text { get expert advice }\end{array}$ & 3.14 & 1.849 & 0.733 \\
\hline I love to visit (street) food festivals & 3.13 & 1.999 & 0.707 \\
\hline $\begin{array}{l}\text { I look for various ways to prepare unusual } \\
\text { meals }\end{array}$ & 3.96 & 1.901 & 0.533 \\
\hline $\begin{array}{c}\text { Going out for dinner is a regular part of our } \\
\text { eating habits }\end{array}$ & 3.84 & 1.912 & 0.513 \\
\hline \multicolumn{4}{|l|}{ Pleasure and interest (Cronbach's alpha: 0.901) } \\
\hline When I eat, I enjoy food very much & 5.51 & 1.441 & 0.846 \\
\hline $\begin{array}{l}\text { Good drinks and food play a major role in my } \\
\text { life }\end{array}$ & 5.32 & 1.549 & 0.806 \\
\hline I am very interested in food & 5.14 & 1.630 & 0.799 \\
\hline $\begin{array}{l}\text { For me, eating is a matter that incorporates all } \\
\text { senses of feeling, smell, taste, and sight }\end{array}$ & 5.41 & 1.583 & 0.712 \\
\hline I am a real foodie at dinner & 4.22 & 1.628 & 0.627 \\
\hline \multicolumn{4}{|l|}{ Novelty preferences (Cronbach's alpha: 0.737) } \\
\hline I buy and eat only familiar foods & 3.91 & 1.776 & -0.712 \\
\hline $\begin{array}{l}\text { I like to try new foods that I have never tasted } \\
\text { before }\end{array}$ & 4.64 & 1.800 & 0.700 \\
\hline I love to try recipes from foreign countries & 4.45 & 1.908 & 0.684 \\
\hline I like to buy and eat exotic foods & 4.19 & 1.843 & 0.654 \\
\hline I would like to attend food tastings & 4.59 & 2.005 & 0.527 \\
\hline $\begin{array}{l}\text { Recipes and articles from magazines from other } \\
\text { cooking traditions make me experiment }\end{array}$ & 4.19 & 1.939 & 0.523 \\
\hline Eating in company (Cronbach's alpha: 0.823) & & & \\
\hline $\begin{array}{c}\text { Dining with friends is an important part of my } \\
\text { social life }\end{array}$ & 4.27 & 1.941 & 0.784 \\
\hline $\begin{array}{l}\text { We often get together with friends to enjoy an } \\
\text { easy-to-cook casual dinner }\end{array}$ & 3.80 & 1.945 & 0.727 \\
\hline $\begin{array}{l}\text { The food taste is much better when I eat in } \\
\text { good company }\end{array}$ & 4.60 & 1.877 & 0.726 \\
\hline $\begin{array}{l}\text { When I serve a dinner to friends, the most } \\
\text { important thing is that we are together }\end{array}$ & 4.98 & 1.753 & 0.699 \\
\hline
\end{tabular}

Note. Scale from 1 'not correct at all' to 7 'that is completely right'. $N=587$.

Table 7 illustrates the statements, factors, and reliability coefficients for the label and buying-related items. The factor analysis reveals that the instrument for label and buying-related items can be divided into four factors. 
Table 7. Factor Analysis Label and Buying-related Items.

\begin{tabular}{|c|c|c|c|}
\hline Factors and the Corresponding Variables & Mean & SD & Factor Loading \\
\hline \multicolumn{4}{|l|}{$\begin{array}{l}\text { Knowlege and trust in food labels (Cronbach's } \\
\text { alpha: } 0.894)\end{array}$} \\
\hline $\begin{array}{c}\text { I have a high degree of confidence in food } \\
\text { labeling }\end{array}$ & 3.67 & 1.638 & 0.838 \\
\hline $\begin{array}{c}\text { Information on food packaging is an important } \\
\text { shopping aid as I trust it }\end{array}$ & 4.03 & 1.713 & 0.815 \\
\hline $\begin{array}{l}\text { I know what the different labels on food } \\
\text { products mean }\end{array}$ & 3.88 & 1.634 & 0.736 \\
\hline I know a lot about food labeling & 3.63 & 1.663 & 0.716 \\
\hline Labels are a good thing & 4.65 & 1.605 & 0.677 \\
\hline $\begin{array}{l}\text { I tend to trust foods that are labeled more than } \\
\text { alternatives without labeling }\end{array}$ & 4.04 & 1.763 & 0.671 \\
\hline $\begin{array}{l}\text { The labeling of food helps me to find the most } \\
\text { environmentally friendly product }\end{array}$ & 4.08 & 1.718 & 0.646 \\
\hline \multicolumn{4}{|l|}{$\begin{array}{c}\text { Environmental concern (Cronbach's alpha: } \\
0.895)\end{array}$} \\
\hline $\begin{array}{l}\text { It bothers me that some people are so little } \\
\text { interested in the environment }\end{array}$ & 4.52 & 1.830 & 0.835 \\
\hline $\begin{array}{l}\text { The use of environmentally friendly products is } \\
\text { a moral obligation for me }\end{array}$ & 4.33 & 1.847 & 0.799 \\
\hline $\begin{array}{c}\text { I'm worried about global environmental } \\
\text { developments }\end{array}$ & 5.07 & 1.766 & 0.790 \\
\hline $\begin{array}{l}\text { For the sake of the enviro., I switched from one } \\
\text { brand to another enviro. friendly brand }\end{array}$ & 3.79 & 1.997 & 0.707 \\
\hline $\begin{array}{c}\text { For the sake of the environment, I often buy } \\
\text { products with an eco-label } \\
\text { Time pressure (Cronbach's alpha: 0.909) }\end{array}$ & 3.81 & 1.919 & 0.673 \\
\hline $\begin{array}{l}\text { I'm often under time pressure when I go } \\
\text { grocery shopping }\end{array}$ & 3.14 & 1.767 & 0.912 \\
\hline I'm in a hurry when I go grocery shopping & 3.16 & 1.780 & 0.907 \\
\hline $\begin{array}{l}\text { I only have limited time for my grocery } \\
\text { shopping }\end{array}$ & 3.32 & 1.843 & 0.880 \\
\hline $\begin{array}{c}\text { I finish my grocery shopping fast as I have } \\
\text { other things to do }\end{array}$ & 3.59 & 1.804 & 0.817 \\
\hline \multicolumn{4}{|l|}{ Information overload (Cronbach's alpha: 0.821) } \\
\hline Information on food packaging confuses me & 3.70 & 1.820 & 0.829 \\
\hline $\begin{array}{l}\text { Information on food packaging is often } \\
\text { incomprehensible }\end{array}$ & 4.45 & 1.725 & 0.824 \\
\hline The whole labeling on food unsettles me & 3.73 & 1.858 & 0.817 \\
\hline $\begin{array}{c}\text { Among the many markings it is not possible to } \\
\text { understand all meanings }\end{array}$ & 4.72 & 1.749 & 0.714 \\
\hline
\end{tabular}

Note. Scale from 1 'not correct at all' to 7 'that is completely right'. $N=587$.

\subsection{Factors Influencing Relative Importance}

Table 8 illustrates the outcomes of the multiple regression analysis. In this case, the score in the carbon footprint quiz, the five food-related lifestyle (FRL) factors, and the four label and buying-related factors-hereinafter named label, information, and time (LIT) factors-were considered as independent variables. In order to reveal possible multicollinearity between the independent variables, the corrected coefficients of determination (R2) are calculated for each regression model. The test of multicollinearity demonstrated a range of the coefficients of determination from 0.041 to 0.226 . Therefore, no serious multicollinearity is present in these four models [33] (pp. 93 ff.). 
Table 8. Regression Results.

\begin{tabular}{|c|c|c|c|c|c|c|c|c|c|c|c|c|}
\hline \multirow[b]{2}{*}{$\begin{array}{l}\text { Independent } \\
\text { Variables }\end{array}$} & \multicolumn{3}{|c|}{$\begin{array}{l}\text { Individual Importance Origin }^{\mathrm{a}} \\
\left(\mathbf{R}^{2} \mathbf{0 . 1 4 0 ) ^ { \mathrm { b } }}\right.\end{array}$} & \multicolumn{3}{|c|}{$\begin{array}{c}\text { Individual Importance Price }{ }^{\mathrm{a}}\left(\mathrm{R}^{2}\right. \\
0.226)^{\mathrm{b}}\end{array}$} & \multicolumn{3}{|c|}{$\begin{array}{c}\text { Individual Importance Organic } \\
\text { Label }^{\mathbf{a}}\left(\mathrm{R}^{2} 0.048\right)^{\mathrm{b}}\end{array}$} & \multicolumn{3}{|c|}{$\begin{array}{c}\text { Individual Importance Climate } \\
\text { Label }^{\mathbf{a}}\left(\mathbf{R}^{2} \mathbf{0 . 0 4 1}\right)^{\mathrm{b}}\end{array}$} \\
\hline & $\begin{array}{l}\text { Standard-Ized } \\
\text { Beta }\end{array}$ & & $p$-Value & $\begin{array}{l}\text { Standard-Ized } \\
\text { Beta }\end{array}$ & & $p$-Value & $\begin{array}{l}\text { Standard-Ized } \\
\text { Beta }\end{array}$ & & $p$-Value & $\begin{array}{l}\text { Standard-Ized } \\
\text { Beta }\end{array}$ & & $p$-Value \\
\hline Score in the quiz ${ }^{c}$ & -0.046 & & 0.249 & 0.053 & & 0.164 & -0.131 & $* * *$ & 0.002 & 0.131 & $* * *$ & 0.002 \\
\hline $\begin{array}{l}\text { FRL factor quality } \\
\text { aspects }\end{array}$ & 0.297 & $* * *$ & 0.000 & -0.171 & $* * *$ & 0.001 & 0.064 & & 0.270 & 0.011 & & 0.850 \\
\hline $\begin{array}{l}\text { FRL factor attending } \\
\text { culinary events } \\
\text { FRL factor pleasure }\end{array}$ & 0.094 & $* *$ & 0.043 & -0.117 & $* * *$ & 0.008 & 0.026 & & 0.592 & 0.037 & & 0.455 \\
\hline $\begin{array}{l}\text { and interest } \\
\text { FRL factor novelty }\end{array}$ & -0.056 & & 0.153 & 0.064 & * & 0.084 & 0.037 & & 0.375 & -0.092 & $* *$ & 0.026 \\
\hline $\begin{array}{c}\text { preferences } \\
\text { FRL factor eating in }\end{array}$ & -0.090 & $* *$ & 0.022 & 0.024 & & 0.514 & 0.087 & $* *$ & 0.036 & -0.007 & & 0.858 \\
\hline $\begin{array}{l}\text { company } \\
\text { LIT factor knowlege }\end{array}$ & 0.002 & & 0.963 & 0.038 & & 0.309 & -0.001 & & 0.983 & -0.075 & * & 0.071 \\
\hline $\begin{array}{c}\text { and trust in food } \\
\text { labels } \\
\text { LIT factor }\end{array}$ & 0.038 & & 0.442 & -0.193 & $* * *$ & 0.000 & 0.109 & $* *$ & 0.034 & 0.121 & $* *$ & 0.019 \\
\hline $\begin{array}{l}\text { environmental } \\
\text { concern } \\
\text { LIT factor time }\end{array}$ & 0.084 & & 0.112 & -0.253 & $* * *$ & 0.000 & 0.103 & * & 0.065 & 0.073 & & 0.191 \\
\hline $\begin{array}{l}\text { pressure } \\
\text { LIT factor }\end{array}$ & 0.017 & & 0.673 & -0.008 & & 0.841 & 0.008 & & 0.854 & -0.016 & & 0.705 \\
\hline information overload & -0.028 & & 0.474 & 0.015 & & 0.690 & -0.016 & & 0.691 & -0.002 & & 0.967 \\
\hline
\end{tabular}


The first column of Table 8 illustrates the findings for the first regression model. By implementing a regression analysis, we can examine whether there is a certain underlying regularity to explain the individual importance of the attribute, origin. In this case, we have three significant factors: "FRL factor quality aspects", "FRL factor attending culinary events", and "FRL factor novelty preferences". This means the more emphasis a respondent places on quality aspects while buying tomatoes, the more important is the attribute of origin for the buying decision. The same pattern applies for the attendance of culinary events. In the case of novelty preferences, the interrelation is negative. Accordingly, the more open a participant is to trying new things, the less importance he or she will attach to the place of origin of vine tomatoes.

In the case of the individual importance of the attribute of price, Table 8 illustrates five significant factors.

Analyzing the individual importance of the attribute of organic label, four significant factors could be identified: "score in quiz", "FRL factor novelty preferences", "LIT factor knowledge and trust in food labels", and "LIT factor environmental concern".

Lastly, Table 8 illustrates, in terms of the individual importance of the attribute climate label, four significant factors: "score in quiz", "FRL factor pleasure and interest", "FRL factor eating in company", and "LIT factor knowledge and trust in food labels".

\section{Discussion}

The relatively low impact of the carbon footprint label in comparison with other food attributes on purchase decisions contrasts with the increasing interest of consumers in the environmental impact of food $[10,12]$. Consumers are more likely to be influenced by the price or origin of the product at the point of sale. Research revealed that the interpretation of the carbon footprint label turned out to be too demanding for the average customer $[1,2,13,14]$. This is due to the difficulty of classifying abstract numbers of greenhouse gas emissions that are shown on the label.

\subsection{Part-worth Utilities and Relative Attribute Importance for the Six Groups}

Low prices increase the purchase probability and higher prices tend to reduce the purchase probability of the product. Therefore, price was found to be the most important attribute in the choice of tomatoes across all six groups. This result is not surprising when considering the outcomes of previous research $[2,14]$.

Furthermore, the implemented CBCA [41] revealed a high purchase likelihood and acceptance for regionally and domestically produced tomatoes. Hereby, the regionally produced tomatoes gain the highest part-worth utility values within the product attribute origin in each of the six groups. The total ranking position of regional origin varies between positions three and five, directly behind the lowest price specifications. Accordingly, it is probable that consumers gain great value, especially trust, from familiar and local production [42]. In consideration of the relative attribute importance, it is noticeable that the origin of the tomatoes is the second most important selling point for four out of six groups. The two remaining groups reveal that the climate label, hence the specific carbon footprint design of each group, is the second most important purchase criterion, right after the price.

In due consideration of the resulting part-worth utilities of the examined carbon footprint label designs, it is noticeable that the values vary relatively widely across the groups. This may imply that some designs are more effective in influencing consumer decision-making than others. All of the groups with extended carbon footprint label designs based on traffic light color-coding gain a relative attribute importance regarding the climate label that is higher than $15.0 \%$. The groups with the highest values in this context are group $3(23.71 \%)$, group $4(24.06 \%)$, and group $2(23.71 \%)$. Notwithstanding, as mentioned before, in the case of group 2 and group 3, the climate label is the second most important selling point after price. This is in line with findings of previous research, revealing that implementing traffic light labeling improves the effect of the carbon footprint label on consumer choices $[2,20]$. 
Lastly, the part-worth utilities of the applied CBCA in this study show comparatively low values for the German organic label across all six groups. The relative attribute importance is placed lowest throughout all the groups. It is noticeable that the relative importance of the organic and the climate label are linked to a certain extent. With increasing impact of the carbon footprint label, the importance of the German organic label is declining.

\subsection{Consumer Segments Resulting from the Latent Class Analysis}

The latent class approach reveals the underlying heterogeneous preferences of the sample when buying tomatoes. Furthermore, the latent class analysis reveals a significant market potential for carbon footprint labelling.

In total, five recurring consumer segments can be observed across the 24 segments (four segments $\mathrm{x}$ six groups).

Price sensitive shoppers. It is notable that each group has at least one customer segment for which price is the prevalent decision criterion. While taking into account the influencing factors that showed significant impacts on the attribute price, it is possible to draw conclusions regarding underlying consumer preferences and behavior. It may be assumed that quality aspects, such as freshness, naturalness, and origin of tomatoes affect price sensitive shoppers to a lesser extent. Furthermore, price sensitive shoppers are less likely to visit culinary events or, in other words, they are not likely to read food blogs on the internet, visit food fairs, or buy products in specialty shops. In addition, environmental concerns, as well as knowledge and trust in food labels, are less pronounced in this segment. Therefore, price sensitive shoppers have weak consciousness of global environmental development and they have either a low degree of knowledge concerning food labelling or a low degree of confidence. This contrasts with the positive influence of the factor pleasure and interest on the price. The more important the role of good food and drink in the life of the participant, the more important the attribute price. In this context, it does not mean that the participants of the segment are more price sensitive, but that price is an indicator of quality food that brings pleasure when consumed.

Domestically oriented shoppers. The participants that were categorized in this segment attach importance to domestically and regionally produced tomatoes. The importance of the attribute is positively affected by the factors quality aspects and attending culinary events. In other words, domestically oriented shoppers put emphasis on regional, natural, and fresh food with a trustworthy character. They tend to inform themselves at food fairs or markets as well as food blogs. On the other side, their novelty preferences are not very pronounced due to their connectedness with domestic food.

Environmentally concerned shoppers. In the groups 3, 4, and 6, the latent class analysis has generated a segment of environmentally concerned shoppers. These segments show a relative importance of the attribute climate label, with a value above $30 \%$, and the remaining attributes are lower in their relative importance. Environmentally concerned shoppers tend to achieve a high score in the carbon footprint quiz and correspondingly have a high knowledge and trust in food labelling systems. On the other hand, factors, such as pleasure and eating in company are not as important to them as the environmental impact of food products. The environmentally concerned shoppers represent the main target group of carbon footprint labelling.

Domestically oriented \& environmentally concerned shoppers. This segment combines the preference for domestically and regionally produced tomatoes with the awareness of environmental issues regarding nutrition. Therefore, the attributes origin and climate label both have relatively high importance values. While taking into account the influencing factors that showed significant impacts on the attributes origin and climate label, it is possible to draw conclusions regarding underlying consumer preferences and behavior. It may be assumed that domestically oriented and environmentally concerned shoppers see connections between domestically produced products and the eco-friendliness of a product.

Holistic shoppers. The survey participants that were allocated to this consumer segment show balanced preferences regarding at least three product attributes. While taking into account the 
influencing factors that showed significant impacts on the three attributes, it is notable that a bunch of influencing indicators are combined here. In other words, consumers of this segment are influenced by many factors and they try to get a holistic picture of the product at the POS.

\subsection{Direct Stated Preferences Regarding Characteristics of Tomatoes}

When comparing the resulting part-worth utilities and the results from the stated preferences task regarding product characteristics of tomatoes using Likert-scales, some notable differences, as well as similarities, appear. Some similarities emerge regarding the price and the origin of the product. In both cases, domestically produced and affordable tomatoes gain the highest preference.

Additionally, environmentally friendly produced tomatoes are stated to be a preferred characteristic. These findings correlate with those from the CBCA and especially with the findings for group 2 and group 3, where the climate label is the second most important selling point. On the other hand, the explicit labelling of tomatoes with a carbon footprint label is stated as the least preferred characteristic in the stated preference task, which, in turn, does not correlate with the outcome of the CBCA. An explanatory approach for this phenomenon could be a combination of insights from the "ethical consumer intention-behavior gap" and the findings that the message of the original carbon footprint labels is too demanding for the average customer [12,14]. Many consumers express their support for environmentally friendly produced products, but they are overburdened with the message of the carbon footprint label. They are not able to classify an abstract number of carbon emissions, which results in the label providing an unclear message [2,14]. This might be an explanation for the differences between the results of the stated preference task and the CBCA in this case.

\subsection{Carbon Footprint Labelling and Label Design}

The present study found, as consistent with earlier research [1,2,12], that carbon footprint labelling significantly influences consumer decision-making on food products. Therefore, the findings support the approach of carbon footprint labelling. In addition, the present research project underlines the outcomes of Meyerding [14], revealing that the original label design - the black footprint indicating the GHG emissions as a continuous variable-is not an effective marketing tool. The original carbon footprint design is not able to close the gap between the consumer need for information and the excessive complexity of the provided information. This is indicated by the negative part-worth utility value of the original label (group 1). The message that is communicated by the label seems to be incomprehensible to the average consumer [13]. The two further labels tested in group 1 show positive part-worth utilities, although being relatively low. This might be due to their ability to transmit a clearer message to the customer, communicating the carbon neutrality of a product or carbon reduction aims of the company. This is in line with findings according to a study by Hartikainen et al. [1], revealing that the carbon reduction and the carbon neutrality label received only modest support among the participants of their study. It is notable that each label design extended with the traffic light color-coding shows better results than the original Carbon Trust label. This confirms the findings of Thøgersen and Nielsen [2] and Grankvist, Dahlstrand and Biel [20], who found a positive impact of traffic light labelling on the effectiveness of the carbon footprint label. Notwithstanding, it is important to note that the carbon footprint label designs applying the traffic light approach differ in their effectiveness of influencing consumer decision-making. This study presents these subtle differences in the label design.

The carbon footprint designs of group 2, group 3, and group 4 show the best performance regarding the relative importance of the climate label for consumer decision-making. In comparison, the attribute of climate label has low relative importance in group 1. Group 2 represents the simplest extension of the original Carbon Trust label with traffic light color-coding. This study confirmed that the simple three-tier ranking significantly amplifies the usefulness of carbon footprint labelling for consumers [2,20]. This version of the label design indicates the absolute carbon emissions, as appearing on the original label from the Carbon Trust. Therefore, the consumers still have the opportunity to 
compare products of different product categories. This might be helpful in order to alter consumer choices away from carbon intensive product categories, such as beef, although it remains demanding for the consumer. Hence, the quick and intuitive comparability within the product category that is made possible by the traffic light labelling will be of greater use for the average consumer.

Moreover, this study examined further stages of the three-tier traffic light labelling with the aim of amplifying the effectiveness of the carbon footprint by the present research building on previous research. The labels of group 3 and group 4 add an extra dimension to the label design, that each of the two label designs made visually accessible in a different way. The labels show absolute emission values, as well as the effort to reduce carbon emissions, as indicated by traffic light color-coding. In addition, the label designs indicate an overall score using three-tier traffic light labelling, enabling a quick and intuitive comparability within the product category. As a result, the consumer might gather considerable environmentally valuable information from these carbon footprint label design alternatives. The approach of adding a dimension for extra information in combination with traffic light labelling applied to each dimension of environmental information aims to solve the dilemma stated above. The dilemma arises because the consumer's need for detailed information and the disadvantages of information overload conflict. In the case of the carbon footprint label designs of groups 3 and 4, the consumers can make their own choice regarding what amount of environmental information they are willing to process. They can decide either that they just need a quick overview of the eco-friendliness of the product using the overall dimension or they are free to take a deeper look at the environmental dimensions, like carbon reduction or the amount of carbon emissions. Their need for information will depend on their consumer preferences or, in the context of this study, which segment of shoppers that the participant belongs to. For example, a participant belonging to the segment of environmentally concerned shoppers will have a greater need for information concerning the environmental friendliness of a product and, furthermore, due to his or her prior knowledge, is more likely to be able to process this kind of information than, for example, a price sensitive shopper for whom this kind of information might be too complex. The findings from this study show that the two designs add value to the carbon footprint for the participants no matter which segment of shoppers they belong. Moreover, this label design represents an approach for solving the dilemma concerning the appropriate amount of information in the context of carbon footprint labelling.

Furthermore, the visual aspect of the label designs should be taken into account. The avoidance of products with negative carbon footprint labels, as figured out by Grankvist, Dahlstrand and Biel [20], is underlined by the findings of the present study. The research suggested that negative labelling is more effective in altering consumer behavior than positive labelling. The participants of group 2 saw the original three-tier traffic light label that was investigated by Thøgersen and Nielsen [2]. The negative (red) label shows a negative part-worth utility. The labels of group 2 and group 3 offer a variety of negative labels due to the three dimensions: carbon emission, carbon reduction, and overall. Almost each form of the label showing at least one dimension within the red (negative) category shows negative part-worth utilities. Due to this design characteristic, the label might be just as effective in altering consumer choices away from carbon-intensive products as towards carbon-friendlier product alternatives.

Moreover, the effectiveness of a carbon footprint label on influencing consumer decision making, as mentioned earlier, depends on the importance of environmental issues to the consumer [43]. Environmentally concerned shoppers, with a higher knowledge and trust in eco-labelling, are more sensitive to the environmental consequences of daily food choices. Consequently, a higher knowledge, and therefore acceptance among consumers, leads to a greater understanding and relevance of carbon footprint labelling.

\section{Conclusions}

This study provides deeper insights into consumers' preferences toward carbon footprint labelling. The research aim was to improve the effectiveness of carbon footprint labelling by investigating 
different design alternatives as an option. Overall, the results of the present study suggest that, regardless of the tested designs, price is always the most influential attribute. However, the impact of the tested designs on stated consumption decisions varied considerably. Hence, the key implication for practitioners that derive from the findings are that a more effective carbon footprint label than the original black footprint label that was established by the Carbon Trust can be designed and applied. For instance, the extension of the original design with traffic light color-coding may help to translate consumer needs into action. The color-coding may enable a quick comparability of products within the same category and manages to make the key information of the carbon footprint label more intuitively understandable. Additionally, the results suggest that, when deciding on a new carbon footprint label, it should be considered that negative labelling is likely to be more effective in altering consumer behavior than positive labelling.

A further extension that was tested in the present study aims to solve the dilemma that commonly arises in the context of carbon footprint labelling around the amount of information. On the one hand, there is a necessity for detailed information, and on the other hand, the high complexity of the message carried by a carbon footprint label causes information overload at POS. The results suggest that adding more dimensions to the label in conjunction with the traffic light labelling allows for establishing different levels of information within the one label.

The present study suffers from the usual limitations when collecting self-reported data in an environment that differs from a real POS situation. The participants have to make trade-off decisions, with consideration of a defined set of attributes, when they state their preferences. The results comprise values of relative attribute importance that help to reveal consumer preferences [44]. Furthermore, the price range and the range of $\mathrm{CO} 2$ emissions chosen for the CBCA might influence the importance of this attribute for consumer decision-making.

An interesting approach for future research could focus on the most promising design alternatives of this study and take a closer look at the subtle cues of the design and gain insights into the mechanism for why it is superior to others. For example, it would be of value to investigate the mechanism of the carbon footprint designs of group 3 and group 4 in focus groups with the aim to reveal whether consumers actually can make use of the different dimensions and the levels of environmental information given. Additionally, a question that should be further explored is why demographic characteristics impact, as shown by previous studies $[5,6]$, the effectiveness of carbon labelling.

Furthermore, it would be interesting to test the effectiveness of the designs in the context of different products and target groups. A follow-up study might also be suggested where the consumers have to make decisions in a more realistic purchase situation. Giving either real or virtual money to the participants, and asking them to evaluate the effectiveness of the carbon footprint label designs through their purchases, could implement this.

Author Contributions: Conceptualization, S.G.H.M. and A.-L.S.; methodology, S.G.H.M.; software, S.G.H.M. and A.-L.S.; validation, A.-L.S.; formal analysis, S.G.H.M.; investigation, S.G.H.M. and A.-L.S.; data curation, A.-L.S.; writing - original draft preparation, A.-L.S.; writing — review and editing of the final paper, M.L. and S.G.H.M.; visualization, S.G.H.M.; supervision, S.G.H.M.; project administration, S.G.H.M.

Funding: This research received no external funding

Conflicts of Interest: The authors declare no conflict of interest.

\section{References}

1. Hartikainen, H.; Roininen, T.; Katajajuuri, J.-M.; Pulkkinen, H. Finnish consumer perceptions of carbon footprints and carbon labelling of food products. J. Clean. Prod. 2014, 73, 285-293. [CrossRef]

2. Thøgersen, J.; Nielsen, K.S. A better carbon footprint label. J. Clean. Prod. 2016, 125, 86-94. [CrossRef]

3. Ostrom, E. Understanding Institutional Diversity; Princeton University Press: Princeton, NJ, USA, 2005.

4. Frey, B.S. Not just for the Money. An Economic Theory of Personal Motivation; Edward Elgar: Cheltenham, UK, 1997. 
5. Zhao, R.; Geng, Y.; Liu, Y.; Tao, X.; Xue, B. Consumers' perception, purchase intention, and willingness to pay for carbon-labeled products: A case study of Chengdu in China. J. Clean. Prod. 2018, 171, 1664-1671. [CrossRef]

6. Li, Q.; Long, R.; Chen, H. Empirical study of the willingness of consumers to purchase low-carbon products by considering carbon labels: A case study. J. Clean. Prod. 2017, 161, 1237-1250. [CrossRef]

7. Antle, J.M. Economic analysis of food safety. In Handbook of Agricultural Economics; 1; Gardner, B.L., Rausser, G.C., Eds.; Elsevier: Amsterdam, Netherlands, 2001; Volume 1, pp. 1083-1136. ISBN 9780444507297.

8. Weinrich, R.; Spiller, A. Developing food labelling strategies. Multi-level labelling. J. Clean. Prod. 2016, 137, 1138-1148. [CrossRef]

9. Kimura, A.; Wada, Y.; Kamada, A.; Masuda, T.; Okamoto, M.; Goto, S. Interactive effects of carbon footprint information and its accessibility on value and subjective qualities of food products. Appetite 2010, 55, 271-278. [CrossRef] [PubMed]

10. Upham, P.; Dendler, L.; Bleda, M. Carbon labelling of grocery products. Public perceptions and potential emissions reductions. J. Clean. Pro-Duction 2011, 19, 348-355. [CrossRef]

11. Walter, S.; Schmidt, M. Carbon Footprints und Carbon Label-eine echte Hilfe bei der Kaufentscheidung? [Carbon footprints and carbon label—A real help with the purchase decision?]. UmweltWirtschaftsForum 2008, 16, 175-181. [CrossRef]

12. Gadema, Z.; Oglethorpe, D. The use and usefulness of carbon labelling food. A policy perspective from a survey of UK supermarket shoppers. Food Policy 2011, 36, 815-822. [CrossRef]

13. Hornibrook, S.; May, C.; Fearne, A. Sustainable development and the consumer. Exploring the role of carbon labelling in retail supply chains. Bus. Strategy Environ. 2015, 24, 266-276. [CrossRef]

14. Meyerding, S.G.H. Consumer preferences for food labels on tomatoes in Germany-A comparison of a quasi-experiment and two stated preference approaches. Appetite 2016, 103, 105-112. [CrossRef] [PubMed]

15. Heinzle, S.L.; Wüstenhagen, R. Dynamic adjustment of eco-labeling schemes and consumer choice - The revision of the EU energy label as a missed opportunity? Bus. Strategy Environ. 2012, 21, 60-70. [CrossRef]

16. Ölander, F.; Thøgersen, J. Informing versus nudging in environmental policy. J. Consum. Policy 2014, 37, 341-356. [CrossRef]

17. Teisl, M.F.; Rubin, J.; Noblet, C.L. Non-dirty dancing? Interactions between eco-labels and consumers. J. Econ. Psychol. 2008, 29, 140-159. [CrossRef]

18. Feunekes, G.I.J.; Gortemaker, I.A.; Willems, A.A.; Lion, R.; van den Kommer, M. Front-of-pack nutrition labelling: Testing effectiveness of different nutrition labelling formats front-of-pack in four European countries. Appetite 2008, 50, 57-70. [CrossRef] [PubMed]

19. Kahnemann, D. Thinking, Fast and Slow; Macmillan: New York, NY, USA, 2011.

20. Grankvist, G.; Dahlstrand, U.; Biel, A. The impact of environmental labelling on consumer preference. Negative vs. positive Labels. J. Consum. Policy 2004, 27, 213-230. [CrossRef]

21. Grunert, K.G.; Wills, J.M. A review of European research on consumer response to nutrition information on food labels. J. Public Health 2007, 15, 385-399. [CrossRef]

22. Bundesanstalt für Landwirtschaft und Ernährung. Pro-Kopf-Verbrauch von Gemüse Wirtschaftsjahr 2015/2016. Available online: https:/ / www.bmel-statistik.de/ernaehrung-fischerei/versorgungsbilanzen/ obst-gemuese-zitrusfruechte-schalen-und-trockenobst/ (accessed on 4 March 2019).

23. AMI. Bio-Möhren verlieren an Dominanz. 2017. Available online: https://www.ami-informiert.de/ fileadmin/newsimages/d2a4b78ff4160e1b938d7594de105668.png (accessed on 4 March 2019).

24. Berry, D. A p-Value to Die For. J. Am. Stat. Assoc. 2017, 112, 895-897. [CrossRef]

25. Backhaus, K.; Erichson, B.; Weiber, R. Fortgeschrittene multivariate Analy-semethoden: Eine anwendungsorientierte Einführung, 2nd ed.; Lehrbuch [Ad-vanced Multivariate Analysis: An Application-Oriented Introduction, Textbook]; Springer Gabler: Berlin, Germany, 2013.

26. Orme, B. Getting Started with Conjoint Analysis: Strategies for Product Design and Pricing Research, 2nd ed.; Research Publishers LLC: Madison, WI, USA, 2010.

27. Balderjahn, I.; Hedergott, D.; Peyer, M. Choice-based conjoint analysis. In Conjointanalyse; Springer: Berlin/Heidelberg, Germany, 2009; pp. 129-146.

28. Green, P.E.; Krieger, A.M.; Wind, Y. Thirty years of conjoint analysis: Re-flections and prospects. Interfaces 2001, 31, 56-73. [CrossRef] 
29. Janssen, M.; Hamm, U. Product labelling in the market for organic food: Consumer preferences and willingness-to-pay for different organic certification logos. Food Qual. Prefer. 2012, 25, 9-22. [CrossRef]

30. Magidson, J.; Vermunt, J.K. Latent class models for clustering: A compari-son with K-means. Can. J. Mark. Res. 2002, 20, 36-43.

31. Brunsø, K.; Grunert, K.; Bredahl, L. An Analysis of National and Cross-National Consumer Segments Using the Food-Related Lifestyle Instrument in Denmark, France, Germany and the United Kingdom; MAPP Working Paper No.35; The Aarhus School of Business: Aarhus, Denmark, 1996.

32. Gunarathne, A.; Hemmerling, S.; Krestel, N.; Zühlsdorf, A.; Spiller, A. A Comparison of Foodies' and Blog Foodies' Nutritional Knowledge and Cooking Skills: Implication for Marketing Strategy Development; University of Goettingen, Department of Agricultural Economics and Rural Development Marketing for Food and Agricultural Products: Göttingen, Germany, 2017.

33. Thøgersen, J.; Haugaard, P.; Olesen, A. Consumer responses to ecolabels. Eur. J. Mark. 2010, 44, $1787-1810$. [CrossRef]

34. Meyerding, S.G.H.; Merz, N. Consumer preferences for organic labels in Germany using the example of apples-Combining choice-based conjoint analysis and eye-tracking measurements. J. Clean. Prod. 2018, 181, 772-783. [CrossRef]

35. AMI. 2014. Available online: https://www.ami-informiert.de/ami-maerkte/maerkte/ami-gartenbau/ ami-meldungen-gartenbau/meldungen-single-ansicht/article/deutschland-verbraucherpreise-fuer-biostrauchtomaten-geringfuegig-gefallen.html (accessed on 15 January 2018).

36. Sawtooth. Lighthouse Studio Help. 2017. Available online: https://www.sawtoothsoftware.com/help/ lighthouse-studio/manual/ (accessed on 10 April 2018).

37. Best for Planning. 2018. Available online: http://www.b4p.media/startseite/ (accessed on 12 January 2018).

38. Magidson, J.; Vermunt, J.K. Latent class models. In The Sage Handbook of Quantitative Methodology for the Social Sciences; Kaplan, D., Ed.; Sage: Thousand Oaks, CA, USA, 2004; pp. 175-198.

39. Nylund, K.L.; Asparouhov, T.; Muthén, B.O. Deciding on the number of classes in latent class analysis and growth mixture modeling. A Monte Carlo simulation study. Struct. Equ. Model. A Multidiscip. J. 2007, 14, 535-569. [CrossRef]

40. Tofighi, D.; Enders, C.K. Identifying the correct number of components in a finite mixture model. Comput. Stat. 2006, 9, 65-78. [CrossRef]

41. Backhaus, K.; Erichson, B.; Plinke, W.; Weiber, R. Multivariate Analysemethoden: Eine anwendungsorientierte Einführung, 13th ed.; Lehrbuch [Multivariate Analysis: An Application-Oriented Introduction, Textbook]; Springer Gabler: Berlin, Germany, 2011.

42. Grunert, K.G. Food quality and safety. Consumer perception and demand. Eur. Rev. Agric. Econ. 2005, 32, 369-391. [CrossRef]

43. Thøgersen, J. Psychological determinants of paying attention to eco-labels in purchase decisions: Model development and multinational validation. J. Consum. Policy 2000, 23, 285-313. [CrossRef]

44. Aspinall, P.A.; Thompson, C.W.; Alves, S.; Sugiyama, T.; Brice, R.; Vickers, A. Preference and relative importance for environmental attributes of neighbourhood open space in older people. Environ. Plan. B Plan. Des. 2010, 37, 1022-1039. [CrossRef]

(C) 2019 by the authors. Licensee MDPI, Basel, Switzerland. This article is an open access article distributed under the terms and conditions of the Creative Commons Attribution (CC BY) license (http://creativecommons.org/licenses/by/4.0/). 